\title{
OECONOMIA
}

COPERNICANA

\section{VOLUME 12 ISSUE 2 JUNE 2021}

p-ISSN 2083-1277, e-ISSN 2353-1827

www.oeconomia.pl

\section{ORIGINAL ARTICLE}

Citation: Liu, N., Xu, Z., \& Skare, M. (2021). The research on COVID-19 and economy from 2019 to 2020: analysis from the perspective of bibliometrics. Oeconomia Copernicana, 12(2), 217-268. doi: 10.24136/oc.2021.009

Contact to corresponding author: xuzeshui@263.net; Sichuan University, No.24 South Section 1, Yihuan Road, Chengdu, China, 610065

Received: 31.04.2021; Revised: 24.05.2021; Accepted: 10.06.2021; Published online: 30.06.2021

Nana Liu

Sichuan University, China

(iD) orcid.org/0000-0001-7091-0139

\section{Zeshui Xu}

Sichuan University, China

(D) orcid.org/0000-0003-3547-2908

\section{Marinko Skare}

Juraj Dobrila University of Pula, Croatia

(D) orcid.org/0000-0001-6426-3692

\section{The research on COVID-19 and economy from 2019 to 2020: analysis from the perspective of bibliometrics}

\author{
JEL Classification: $A 10 ; A 14$
}

Keywords: COVID-19; economy; bibliometrics

\begin{abstract}
Research background: The outbreak and spread of COVID-19 brought disastrous influences to the development of human society, especially the development of economy.

Purpose of the article: Considering that knowing about the situations of the existing studies about COVID-19 and economy is not only helpful to understand the research progress and the connections between COVID-19 and economy, but also provides effective suggestions for fighting against COVID-19 and protecting economy, this paper analyzes the existing studies on COVID-19 and economy from the perspective of bibliometrics.

Methods: Firstly, the discussion starts from the statistical analysis, in which the basic distributions of the studies on different countries/regions, different publication sources, different publication years, etc., are presented. Then, the paper shows the cooperation situations of the researchers from analyzing the related citation networks, co-citation networks and cooperation networks. Further, the theme analysis of the related studies is presented, in which the related co-occurrence
\end{abstract}


networks are shown, and then the detailed analyses of the studies are introduced. Based on these analyses, the discussions about future research are presented, and finally we draw a conclusion. Findings \& value added: The analyses not only present the basic situation on the research about COVID-19 and Economy, but also show the future research trends, which can provide meaningful research expectations.

\section{Introduction}

At the end of 2019, the outbreak of the coronavirus disease 2019 (COVID19) definitely brought great disasters for the development of society in many aspects (Korzeb \& Niedziolka, 2020; Kuc-Czarnecka, 2020; Williams, 2020). Tens of thousands of people all over the world have been affected by the pandemic terribly (Kufel, 2020; Nicola et al., 2020; Zinecker et al., 2021). Firstly, humans' physical health is under enormous threats. The influence of the COVID-19 is continuing, and it seems like a long-term war between the virus and humans. Besides, COVID-19 also brought challenges for humans' psychological health. It is not only a medical phenomenon, but also causes destructive anxiety, stress, stigma and xenophobia (Javed et al., 2020; Moore \& Kolencik, 2020; Popescu Ljungholm \& Olah, 2020). The psychological impacts of COVID-19 on different people are also different. The COVID-19 brings dramatic negative influences on homeless people, the elder people, the disable people, and the people with mental disorder (Javed et al., 2020). Besides, the pandemic usually has disastrous influences on the society development, especially the economy (Nicola et al., 2020). The economic impacts of COVID-19 have extended to different industries, including agriculture, petroleum and oil, manufacturing, education, finance, healthcare and the pharmaceutical industry, hospitality, tourism and aviation, real estate and housing sector, etc., and the different industries are all facing recession (Nicola et al., 2020).

In order to eliminate the economic impacts of COVID-19, many countries/regions have taken different measures. The measures, such as social distancing and lockdown, definitely work on the control of the pandemic (Atalan, 2020; Newbold et al., 2020). Besides, some countries/regions also stimulate economy through some financial policies. For example, the European Commission has allocated €25bn in investment funds and agreed to a more relaxed approach to budget rules, which can encourage the public consumption and support the development of enterprises (Nicola et al., 2020).

Bibliometrics analysis is a technique that provides quantitative analysis of research publications in a domain combining with statistical and mathematical skills (Cooper, 2015). It has been applied to many research fields to 
present the research features and trends clearly. Initially, the research productivity can be evaluated through some mathematical and statistical methods (Chen et al., 2014). Then, through using some software, such as VOS viewer, Citespace, etc., the connections of the existing studies can be presented vividly, which is helpful to show the bibliometric characteristics of the studies in a particular field. In addition, the themes of the existing studies can be shown through the related keyword co-occurrence networks, which allows investigators to grasp the development priorities and trends in the field, and meanwhile helps policy makers to strategize the potential research areas (Mohadab et al., 2020). In the field of COVID-19, there have been some research publications focusing on the analysis of the literature from the perspective of bibliometrics. Some of them discussed the global scientific research on COVID-19, and most of these publications analyzed the scientific productions related to COVID-19 (Costa et al., 2020; Dehghanbanadaki et al., 2020; Farooq et al., 2021; Mohadab et al., 2020; Oliveira et al., 2021). Meanwhile, in these publications, some authors summarized the hotspots and explored the future trends of the research (Gautam et al., 2020; Lou et al., 2020; Mao et al., 2020; Yang et al., 2020; Yu et al., 2020). Also, there have been some studies that analyzed the international cooperation and interdisciplinary cooperation situations (Dehghanbanadaki et al., 2020). In addition, some of the bibliometrics analyses are based on selected or notable publications. For example, Borku Uysal et al. (2021) mainly selected the most notable 100 articles of COVID-19, Afshar and Tabrizi (2020) chose 100 highly-cited articles about COVID-19, and Elhawary et al. (2020) took the most 50 cited papers as their research objectives. Similarly, some bibliometrics-based studies focus on the publications in some specific time periods, such as the first eight months in 2020 (Furstenau et al., 2021), the early stage of the outbreak (Gong Y. et al., 2020; Zyoud \& Al-Jabi, 2020), etc. There are also some bibliometrics analyses that focus on some specific countries or regions (Gallegos et al., 2020; Raju \& Patil, 2020) or publication sources (Oh \& Kim, 2020). Beyond that, most of the bibliometrics analyses focus on some specific topics or fields, including COVID-19 and environment (CasadoAranda et al., 2021; Zyoud \& Zyoud, 2020), mental health and COVID-19 (Maalouf et al., 2021), COVID-19 and machine learning (Chiroma et al., 2020; De Felice \& Polimeni, 2020), COVID-19 and business and management (Rodrigues et al., 2020; Verma \& Gustafsson, 2020), etc.

Through investigating the aforementioned review of bibliometrics on COVID-19, we can find that there are no related research on COVID-19 and economy. Knowing about the relationships between the economy and COVID-19 is useful for us to understand the economic influences of 
COVID-19. Besides, through analyzing the related studies, we can also know about how economic factors affect the transmission of COVID-19, so that to take measures efficiently to prevent the spread of the pandemic. Hence, it is meaningful to conduct a bibliometrics analysis on the studies about COVID-19 and economy. In this paper, we firstly conduct the statistical analysis on the existing studies of COVID-19 and economy, in which the distributions of the studies on different publication years, different countries/regions, different publication sources, etc. are shown. Then, some citation networks, co-citation networks and cooperation networks are presented to explore the relationships among the existing studies. Further, the theme analysis is conducted by combining with keywords co-occurrence networks and literature analysis. Based on the analyses, some discussions on future research are presented.

The contributions of this paper are: (1) we firstly provide a relatively comprehensive bibliometrics analysis on COVID-19 and economy. The research can help us to understand the related research progress clearly; (2) Through the bibliometrics analysis, the citation and cooperation among the existing studies and some researchers, some institutions, etc., can be investigated, which is meaningful to understand the connections among the existing studies; (3) Through the analysis of theme, the current research features are presented vividly, from which the hotspots and future trends can be explored; (4) The bibliometrics analysis can provide effective suggestions for policy makers to fight against COVID-19 and protect economy as much as possible.

The rest of the paper is shown as follows: in Section 2, we introduce the method to collect data, and some basic statistical characteristics of the studies related to COVID-19 and economy. Then, we present the citation and cooperation situations in Sections 3. Section 4 mainly analyzes the themes of these studies, in which the keywords co-occurrence networks are shown firstly, and then the related literature analyses are presented. In Section 5, we discuss some future research directions. Finally, in Section 6, we draw a conclusion for the paper.

\section{General analysis}

In this section, we firstly introduce the idea for data collection. Then, the basic statistical features of the studies are presented. 


\section{Data collection}

Nowadays, there are many databases that provide literature information, such as IEEE Explore, Springer, Google Scholar, Web of Science, etc. Considering that Web of Science is one of the most classical and common-used databases, and covers the oldest publications dating back to 1900, and provides better citation information (Falagas et al., 2008; Leslie \& Chris, 2013), we choose Web of Science to collect the literature information. Besides, considering that the literature provided by Web of Science can be segmented to different categories and its core database provides relatively comprehensive and accurate information, we mainly use the core database of Web of Science to retrieve literature.

In order to explore the studies on COVID-19 and economy, we retrieve the literature through the following steps. Firstly, we retrieve the articles in Web of Science through theme retrieving with the theme words in Figure 1. After we finish the literature selection under each theme words, we combine the retrieving results and remove the duplicate articles. Then, the final sample can be determined.

\section{Basic characteristics of the publications}

In this part, we mainly present the general characteristics of the existing studies from the following perspectives: i.e., the distribution over publication years, the distribution over countries/regions, the categories of the publications, and the basic publication-based information.

\section{The distribution over publication years}

As Figure 2 shows, there are 601 articles that studied the COVID-19 and economy from December 2019 to December 2020, and 1 of them published in 2019, 593 of them published in 2020, 7 of them will be published in 2021. It is clear that the issues about economy during COVID-19 have attracted lots of attention.

\section{The categories of the publications}

In the case of core data base of Web of Science, the publications have been segmented to the following 9 categories, which is relatively diversiform. In Figure 3, we can see that the number of article is up to 449, more than $70 \%$ of all the publications, which occupies the largest proportion. Then, the number of editorial is up to 85 and ranks at the second. Following 
is the early access, the number of which is up to 79 and ranks at the third. Besides, there are 25 reviews, 25 letters, 10 news items, 6 meeting abstracts, 1 data paper, and 1 book review, but the total number of these five kinds of publications is 68 , which is no more than the number of early access.

\section{The distribution over publication sources}

The documents are published on 370 publication sources, in which the top 11 prolific sources are shown in Table 1 . In order to show their basic publication situations and impacts, we use four basic indicators to present the quantity features of these sources., i.e., the total number of publications (TP), the proposition of TP among the 601 publication (\% of 601), the total number of citations (TC), the average number of citations per publication (TC/TP), and the H-index. From the values of the indicators, we can see that the journal "Sustainability" publishes the most papers from December 2019 to December 2020 on the topic of COVID-19 and economy. "Journal of Public Affairs" ranks at the second position, following is "Survey Research Methods". For the indicator TC, the performances of "Tourism Geographies" and "Finance Research Letters" are extraordinary and better than other publication sources obviously. Especially "Tourism Geographies", its TC/TP is outperforming, which can present the high impact of the papers published in this journal. The similar inference can also be gotten from its performance on $\mathrm{H}$-index.

To show the related indictors vividly, Figure 4 is presented. In the chart, the principle vertical axis denotes the values of TP and TC, the secondary vertical axis denotes the values of $\mathrm{H}$-index. We can see the quantity relations among them clearly, and it is also obvious that the most two influenced journals in these top-11 prolific source publications are "Tourism Geographies" and "Finance Research Letters".

\section{The distribution over countries/regions}

Figure 5 shows the countries/regions distribution of the retrieved documents. The documents are distributed in 83 countries/regions all over the world. The deeper the color, the more publications from that area. From Figure 5, we can see that the color in the USA is the deepest, then is China. Some countries/regions in Europe, India and Australia also have relatively deep color.

To better explore the distribution of the publications on different countries/regions, we present the basic four indicators for the most 10 prolific 
countries/regions, which are shown in Table 2. We can see that there are 2 Asian countries/regions (China and India), 5 European countries/regions (England, Italy, Germany, Russa, Spain), 2 countries from North America (USA and Canada) and 1 country/region in Oceania (Australia). The publications from the USA are the most (up to 123), following is the publications from China (up to 69). The number of the publications in England is the third in the list. Besides, the number of the related publications from the USA is obviously more than other countries, and the publication numbers in China and England are in the interval $[60,70]$. The number of the publications from other seven countries/regions are all lower than 50. Besides, it is clear that the top 3 prolific countries/regions produce more than $40 \%$ publications of all the publications.

Referring to the citation situation, the publications from the top 3 prolific countries/regions have been cited more than 100 times, in which the performance of England is the excellent with the citation of 705 times, then there is the USA, with China following. From the indicator TC/TP, it is undoubted that the performance of England is the best. Besides, Canada, which is the ninth based on TP, ranks only second to England on the indicator TC/TP. For H-index, USA ranks at the first position, China and England rank after it with the $\mathrm{H}$-index 9 and 8, respectively. To present the variation of the TP, TC and H-index clearly, Figure 6 put these three indicators together, in which the principle vertical axis denotes the values of TP and TC, the secondary vertical axis denotes the values of H-index. From the histograms and the line, the relative quantity relationships between these three indicators are clearer.

Further, we use the following five indicators to primarily explore the international cooperation of the top-10 prolific countries/regions (Yu et al., 2017), i.e., the number of cooperated publications (NCP), the proportion of the NCP among the TP (\% of TP), the number of the citations of the cooperated publications (CTCP), the average number of the citation per cooperated publication (CTCP/NCP) and the number of the countries/regions that cooperate with the target countries/regions (NCC), which are shown in Table 3. From the values of the indicators, we can see that the USA's performance on NCP is the best, following is England and China. Investigating the $\%$ of TP, we can see that England, Germany, and Spain have outstanding performance with more than $50 \%$ cooperated publications, especially England and Germany. Therefore, more than half of the publications from these three countries/regions are cooperated with other countries/regions. In addition, for the values of CTCP/NCP, Canada's performance is prominent, which is up to 10.86. That is to say, although the NCP of Canada is 8 , the average influences of the publications are strong and worth referring to. 
The values of CTCP/NCP in England, Italy, Australia and India are still outstanding, even better than the most prolific countries/regions.

From all the analyses on distribution of the papers on different countries/regions, we can see that the USA, China and England are the top-3 prolific countries/regions. Their citations and $\mathrm{H}$-indices are also higher than other seven countries/regions, especially England. When it comes to the basic cooperation situation of the different countries/regions, the USA, China and England also have good performance on some absolute indicators, such as NCP, NCC and CTCP. However, for some relative indicators, such as \% of TP and TCP/NCP, the advantages of Germany, Canada, India are emerging, which shows their positive cooperation with other countries/regions and also presents the significant impacts of their cooperated research results.

\section{The citation and cooperation analysis}

In this section, we mainly explore the literature from the perspective of citation and cooperation situation. Firstly, the general citation situation is presented, then the citation networks of the documents and the co-citation networks of the references are presented. Further, the cooperation networks based on different countries/regions, different institutions, and different authors are analyzed.

\section{The citation analysis}

The total citation times of all the studies are up to 2381 , the average number of the citation per publication is 3.96 , and the $\mathrm{H}$-index is up to 23 . Table 4 shows the basic information of the top- 10 cited documents. We can see that the most cited publication with 364 citation times, which is higher than other publications obviously. The citation times of other documents in the list are all lower 60. Figure 7 shows citation network of the studies, in which the size of the node denotes the number of the citation. During the analysis process, we set the minimum of citation of a document to 1 . The left part in Figure 7 shows the citation situation of all the documents that have at least 1 citation. The documents are segmented to 456 categories, and many of them are separated. It is clear that the document written by Nicola et al. (2020) is the most cited.

To present the conspicuous linkages among the documents, the largest sub-network of the connected items is shown on the right side in Figure 7, in which there are 71 items. In the sub-network, the documents are seg- 
mented to 12 clusters, in which cluster one contains 12 items, cluster two contains 8 items, cluster three contains 8 items, cluster four contains 6 items, cluster five contains 6 items, cluster six contains 6 items, cluster seven contains 5 items, cluster eight contains 5 items, cluster nine contains 5 items and cluster ten contains 4 items., cluster eleven has 3 items and cluster twelve has 3 items. For the cluster one, the nodes are denoted in red, in which the relatively 3 higher cited documents are written by Ali M. et al. (2020), Haroon et al. (2020) and Phan and Narayan (2020). For cluster two, the nodes are located on the bottom right corner, in which the most cited document is written by Hall et al. (2020) and the citation relationships in this cluster seem simpler in a chain-shape. The nodes in cluster three are blue, in which the document written by Goodell (2020) is the most cited. For cluster four, the nodes are yellow and the most cited document is written by Sharif et al. (2020). In cluster five, the nodes are purple, and the most cited document is written by Nicola et al. (2020). In cluster six, the nodes are sky blue, the citation of each document is lower than 20, and the most cited document is written by Ataguba (2020). The nodes in cluster seven are orange, and the citations of documents in this cluster are all also lower than 20, in which the document written by Ramelli and Wagner (2020) is the most cited. For cluster eight, the nodes are brown, and the document written by Gupta et al. (2020) is the most cited. In cluster nine, the nodes are pink and the most cited document is written by Liu H. et al. (2020). The nodes in cluster ten is light pink, and the document written by Ashraf (2020) is the most cited. In cluster eleven, the nodes are light green, and the most cited document is written by Zhang D. et al. (2020). For cluster twelve, the nodes are light blue, the document written by Al-Awadhi et al. (2020) is the most cited.

To further explore the citation relationships of the documents, we analyze the co-citation situation on references level, and we set the minimum citation of a cited reference to 4 . As Figure 8 shows, the cited references can be segmented to 6 clusters, in which there are 59 items in cluster one (the red part), 27 items in cluster two (the green part), 23 items in cluster three (the blue part), 20 items in cluster four (the yellow part), 16 items in cluster five (the purple part), and 11 items in cluster six (the sky-blue part).

The nodes in the figure denote the citations of the references, and the more cited the reference, the larger the corresponding node. The top-12 cited references (the citations are all more than 12) are shown in Table 5, in which we can see that six of them are distributed evenly to cluster one and cluster four, six of them are distributed in cluster two, cluster five and cluster six evenly. The links and the total link strength denote the connected strength of the target reference with other references. In the top-12 cited 
references, the most cited reference also has the largest links and the total link strength. Besides, these top-12 cited references are all have relatively larger links and total link strength in their corresponding clusters, which also illustrates that these 12 references have significant referring value in the area of COVID-19 and economy research.

\section{The cooperation network}

After analyzing the citation situation, in this subsection, we analyze the cooperation networks of the related studies from the perspectives of different countries/regions, different institutions and different authors.

\section{The co-cooperation network on different countries/regions}

Figure 9 shows the cooperation network on the level of countries/regions, in which we set the minimum number of documents of a country to 1 , and the minimum number of citations of a country to 0 . The size of the node denotes the number of the published documents of the country/region, and the larger the node, the more published documents in that country/region. In the figure, the left part denotes the whole cooperation network composed by the documents that satisfy the thresholds, the right part denotes the largest sub-network in the whole network, and the nodes of the same colors are in the same cluster. In the sub-network, the 70 items are segmented to 12 clusters, in which 9 items in cluster one (in red), 8 items in cluster two (in green), cluster three (in blue), cluster four (in yellow), cluster five (in purple) and cluster six (in sky-blue) all have 7 items, cluster seven (in orange) and cluster eights (in brown) all have 6 items, cluster nine (in pink) and cluster ten (in light pink) both have 5 items, cluster eleven (in light green) has 3 items. Besides, in the 8 countries/regions in cluster two, 7 of them are European countries/regions and 1 of them is Asian country/region. In cluster five, the countries/regions are all located in Asia. Similarly, the countries/regions in cluster ten are all European countries/regions. The remaining clusters show a trend of diversified cooperation. That is to say, the geographical location may have influence on the cooperation among different countries/regions, and the countries/regions in the same area seem to cooperate conveniently, but the diversified cooperation is an unstoppable trend.

In Table 6, the basic cooperation indicators of the top-10 prolific countries/regions are listed, in which "links" denotes the number of countries/regions that cooperate with the target country/region, "total link strength" denotes the times of collaborations between the connected coun- 
tries/regions (Wang et al., 2021). Firstly, we can see that there are 3 of the countries/regions that belong to cluster two, two of the countries/regions belong to cluster six, and the remaining 5 countries are evenly distributed in cluster three, cluster five, cluster eight, cluster nine and cluster ten. From the table, the top-3 prolific countries/regions also have the relatively high links, total link strength and citation, especially England, which performs brilliantly in citation and also has the highest links. Besides, the links and total link strength of these ten countries/regions are higher than other countries/regions in their corresponding clusters, which reflects that these countries/regions have strong cooperation with other countries/regions.

\section{The co-cooperation network on different intuitions}

Figure 10 shows the cooperation network on the level of institutions, in which we set the thresholds of minimum number of documents of an institution to 1 , and the minimum number of citations of an institution to 0 . In the figure, the size of the node denotes the number of the published documents in the institution, and the larger the node, the more published documents in this institution. The left part of the figure shows the whole cooperation network, and there are some organizations that are not connected with each other. To present the key cooperation network clearly, we present the largest cooperation sub-network on the right part in the figure. There are 159 institutions in the largest cooperation sub-network, and the different institutions are segmented to 15 clusters, in which cluster one (in red) and cluster two (in green) both have 15 items, cluster three (in blue) and cluster four (in yellow) both have 14 items cluster five (in purple) and cluster six (in sky-blue) both have 13 items, cluster seven has 12 items (in orange), cluster eight has 10 items (in brown), cluster nine (in pink) and cluster ten (in light pink) both have 9 items, cluster eleven (in light green) and cluster twelve both have 8 items (in light blue), cluster thirteen (in light yellow) and cluster fourteen both have 7 items (in light purple), cluster fifteen has 5 items (in light sky blue). From the largest cooperation sub-network, it is clear that the different clusters are not independent, there are some connections among different clusters as well.

Table 7 shows the top-11 prolific institutions (the number of published papers is 4 at least) in the largest cooperation sub-network, in which 3 of the institutions belong to cluster three, 2 of the institutions belong to cluster four, 2 of them belong to cluster five, the remaining institutions belong to cluster eight, cluster nine, cluster eleven and cluster fourteen evenly. Besides, most of the top-11 prolific institutions are in North America and Europe. Similarly, the links and total link strength of these 11 institutions are 
higher than other institutions in their corresponding clusters, which reflects that these institutions have strong cooperation with other institutions. From the perspectives of links and total link strength, University of Sydney has the excellent performance, whereas from the perspective of citations, Kings College of London is the most outstanding.

\section{The co-cooperation network on different authors}

Figure 11 shows the author-level cooperation network, in which we set the thresholds of minimum number of documents of an author to 1, and the minimum number of citations of an author to 0 . In the figure, the left part shows the whole author-level cooperation network, in which there are 1716 authors and most of them are not connected with each other. In order to present the key author-level cooperation network, the largest author-level cooperation sub-network is shown on the right of the figure. There are 19 authors in the largest author-level cooperation sub-network, the size of the node denotes the number of the published documents of the author, and the larger the node, the more published documents of the author. In the largest author-level cooperation sub-network, the authors are segmented to 4 clusters, in which cluster one has 6 authors (in red), cluster two has 5 authors (in green), cluster three has 5 authors (in blue), and cluster four has 3 authors (in yellow).

Table 8 shows the top-10 prolific authors in the largest author-level cooperation sub-network, in which four of them belong to cluster one, three of them belong to cluster three, two of them belong to cluster four, one of them belongs to cluster two. In the researchers, the author Mckee, Martin has the highest links, total link strength and citations. Besides, the author Stubbs Thomas who just published two papers also have an outstanding citation with 70 . Investigating the author-level largest cooperation subnetwork in Figure 11, we can see that, the authors in cluster three also have cooperation relationship with the authors in cluster one and cluster two, the authors in cluster two not only have cooperation with authors in cluster three, but also the authors in cluster four. This is consistent with the result that the authors in these two clusters have relatively higher links and total link strength.

\section{The exploration of the themes}

In this section, we mainly explore the different themes of the existing studies. Firstly, the keyword co-occurrence analysis is conducted to show the 
basic connection among the studies. Then, we use the bibliometrics-based term analysis technique to investigate the main themes of the existing studies. Further, we segment the existing literature to different clusters based on the different themes, and present the main research topics under the different themes.

\section{The keyword co-occurrence analysis}

We firstly conduct the keyword co-occurrence analysis using VOS viewer. During the process, we choose all keywords as the foundation of the analysis, and we set the minimum number of occurrences of a keyword to 5. Besides, since there are some words that have the same meanings or they are singular and plural, we create word sets to merge them. Then, we can see the keyword co-occurrence network as Figure 12 shows, in which the size of the node denotes the number of the occurrence, the larger the node, the more times the keyword appears. From the figure, we can see that the keywords are segmented into 10 clusters, in which cluster one contains 12 words (in red), cluster two contains 12 words (in green), cluster three (in blue) contains 10 words, cluster four has 9 words (in yellow), cluster five contains 8 words (in purple), cluster six contains 6 words (in sky blue), cluster seven contains 5 words (in orange), cluster eight contains 4 words (in brown), cluster nine contains 3 words (in pink), cluster ten contains 2 words (in light red). We can see that the keyword "covid-19" comes up the most often, and the words "pandemic", "impact", "economy", "risk", "economic growth", etc. also have relatively high occurrence.

We list the keywords, the occurrences of which are higher than 16 in Table 9. We can see that there are nine keywords that evenly belong to cluster two, cluster three and cluster five, respectively. The indicator "links" denotes the number of other keywords that appear together with the target keyword in the literature, and the indicator "total link strength" denotes the total number of the papers that includes the target keyword and the other keywords linked to the target keyword. Investigating the result of the keyword co-occurrence analysis, we find that the keywords that have higher occurrences also have higher links and total link strengths. For example, in Figure 12 and Table 9, it is clear that the keyword "covid-19" connects with 70 other keywords, and the total link strength of it is up to 465 . Definitely, it is the most central keyword. From the keyword in Table 9, we can also infer that the research on COVID-19 and economy has paid lots of attention to the economic influences of COVID-19, the risks, the stock market, and the policies, etc. 


\section{The term co-occurrence analysis}

To further investigate the different themes of the existing studies, we use VOS viewer to analyze the terms in the title and abstract fields of the existing studies, and we set the minimum occurrences of a term to 10 , meanwhile we choose all the relevant terms to construct the term co-occurrence network as Figure 13 shows. In the figure, the left part is the whole network, the right part is the largest sub-network, and the size of the node denotes the number of the occurrence, the larger the node, the more times the term appears. Similarly, since there are some words that have the same meanings or they are singular and plural, we create word sets to merge them.

In the construction of the term co-occurrence network, the 257 relevant terms are segmented to 5 clusters, in which cluster one contains 82 items (in red), cluster two has 70 items (in green), cluster three contains 63 terms (in blue), cluster four contains 38 terms (in yellow), cluster five has 4 terms (in purple). The distance among the terms reflects the similarity between them, the larger the distance, the larger the difference. In the figure, we can see that there are two terms that are far from other terms, i.e., "political consequence" and "cross section approach comment", which means that these two terms are a little different from other terms. Besides, we can see that there are some terms that have higher occurrences than other terms, such as "covid-19", "pandemic", "impact", "economy", "crisis", and "country", etc., which are similar to the high-occurrence keywords in the keyword co-occurrence analysis.

Table 10 shows the top-10 terms on the occurrence, in which 4 of them belong to the cluster three, the remaining 6 of them belong to cluster two, cluster four, and cluster five evenly. In the term co-occurrence analysis, the links denote the number of the terms connected with the target term, and the total link strength denotes the total strength of the co-occurrence connection between the target term and other terms. Investigating the results, we can see that the terms that have relatively high occurrences also have high links and total link strength both in their corresponding clusters and the whole terms. Referring to the terms in different clusters, we hold the view that the terms in the cluster one are more related to people's livelihood, including employment, income, hospitalization, education, etc. The terms in the cluster two may relate to the activities or measures during the COVID-19 or the post-pandemic era, since there are some terms like: "policy", "strategy", "post covid", "sustainability", "economic recovery", etc. The terms in the cluster three mainly relate to the economic influence of the COVID-19 on different countries/regions, since there are many terms about 
the name of the countries, and the terms like "effect", "country", "impact", etc. The terms in cluster four are similar to the terms in the cluster three, including "influence", "economic growth", etc., which reflects the economic influences of the COVID-19. While, there are also many terms about industries, such as "supply chain", "tourism", "oil price", etc. Therefore, we think that this cluster is related to the economic influences of the COVID-19 on different industries. The terms in cluster five are more related to the policies during the pandemic, since there are terms like: "political consequence", "pandemic".

\section{Literature analysis}

In this subsection, we mainly segment the existing studies related to COVID-19 and economy through their main topics. As Figure 14 shows, most of the existing studies analyzed the impacts of COVID-19 on economy, and the researchers usually discussed the general economic impacts of COVID-19, the pandemic's economic influences on different countries/regions, different industries, etc. In addition, some of the researchers evaluated the economic situations after the outbreak of COVID-19. There have been also some studies that analyzed economic theories combining with the influences of COVID-19. Apart from analyzing the economic impacts of COVID-19, the issues on proposing efficient economic measures or policies to stop the spread of COVID-19 and protect people from the threat of COVID-19 have received lots of attention. Meanwhile, the detailed analyses of some measures or policies are also meaningful to explore the relationships between COVID-19 and economy, in which most of them focus on the challenges on the measures, the proposal of measures and the analyses of the measures. Beyond that, considering that some economic factors are correlated to the transmission of COVID-19 and some economic measures' effectiveness are also worthy to be noted, the related issues on transmission of COVID-19 and effectiveness of measures are also studied. Apart from the research based on the issues that have happened, there have been some studies that paid attention to the future expectations and developments of economy in the post-pandemic era. Hence, we mainly discuss the existing studies from the following four parts, i.e., the economic impacts of COVID-19, the issues on measures, the influences of economy and related measures on COVID-19, and the economic development in the postpandemic era. 


\section{The economic impacts of COVID-19}

1. The general analyses of the pandemic's economic impacts

In the existing studies, there have been lots of papers that explored the economic impacts of COVID-19 generally. In these studies, researchers often discussed some issues related to environment, politics, psychology, etc. Kapecki (2020) pointed out that it is difficult to predict the influences of the pandemic, especially when it is lack of historical data for reference. The abrupt outbreak of COVID-19 led the economy to a terrible situation (Karabag, 2020). In a letter to editorial, Gupta et al. (2020) held the view that the pandemic definitely had major consequence on the global economy and it would lower global gross domestic growth largely. The economic impacts of COVID-19 generally can be analyzed from different perspectives. For example, Nicola et al. (2020) reviewed the social-economic implications of COVID-19, and summarized the economic effects of the pandemic on primary sector (including agriculture, petroleum and oil), secondary sector (i.e., manufacturing industry) and tertiary sectors (including education, finance industry, healthcare and the pharmaceutical industry, hospitality, tourism and aviation, real estate and housing sector, sports industry, information technology, media, research and development, and food sector). Finally, they pointed out that it was necessary for governments to take resilient and strong measures to fight against COVID-19, meanwhile making medium and long-term plans for the recovery of economy. Beyond that, Zhang (2020) put forwards with five basic insights related to the economic impacts of COVID-19. In addition, some researchers discussed the economic risk factors brought by the pandemic, meanwhile, proposed the method to measure the economic risks (Noy et al., 2020).

2. The analyses of the pandemic's economic impacts on different countries/regions

The economic impacts of COVID-19 have also been analyzed in different countries/regions. In the existing 601 papers, the economic impacts of COVID-19 are analyzed in more than 25 countries/regions, including China, the USA, England, Africa, etc. Specifically, Yue et al. (2020) used four models to predict the infections, death and GDP of China, so that assessed the economic impacts of COVID-19 comprehensively. In their research, they held the view that although the outbreak of COVID-19 brought huge economic impacts in China, China's economy will recover soon and develop steadily. From the perspective of suicide rate, Mamun and Ullah (2020) 
analyzed the negative effects that lockdown-related economic recession caused, and they pointed out that the devasting economic crisis would continue months, even years. Debata et al. (2020) also pointed out that the pandemic affected the Indian economy from many aspects, such as agriculture sector, manufacturing sector, etc. Beyond that, some researchers (Debata et al., 2020) also disclosed that the economic impacts are not as severe as the health impacts in the north part of Italy. Besides, they found that the empathy and the response style would affect the perceived impact on the economy. In the UK, some researchers investigated that the ethnic and native-immigrant inequalities are intersecting in the economic impacts of COVID-19, and the black, Asian and minority ethnic migrants are riskier than the UK-born white British to lose job (Hu, 2020). Besides, some researchers also discussed the economic impacts of COVID-19 in some undeveloped areas (Mamun \& Ullah, 2020; Porsse et al., 2020; Suryahadi et al., 2020). For example, Ataguba (2020) analyzed the economic impacts of COVID-19 in Africa from the perspectives of microeconomic costs and macroeconomic burden, and finally pointed out that it was difficult to ascertain the full economic impacts of COVID-19 in African countries. All in all, the pandemic brought huge stress to different countries/regions, and the countries/regions all over the world are facing the unprecedented challenges in the all aspects of economy.

3. The analyses of the pandemic's economic impacts on different industries

The discussions of the economic impacts of COVID-19 for different industries are various, which involves people's food, clothing, shelter and transportation, etc. We segment the related studies to the following 10 classifications, in which we can see that the topics about finance, business, agriculture are more various (see Figure 15). In the research of the impacts on finance (Ali M. et al., 2020; Goodell, 2020; Haroon \& Rizvi, 2020; Phan \& Narayan, 2020), researchers usually took the topics on stock, currency, financial system, gold and real estate trusts, insurance, and cryptocurrency, etc., in which the focus on stock market is the most, as stock is one of the most active financial indicators (Phan \& Narayan, 2020). For the research about medical and health, many researchers discussed the economic challenges of COVID-19 on different medical departments, such as elective surgery (Best et al., 2020), dental surgery (Chamorro-Petronacci et al., 2020; Patel, 2020), etc. For human resources part, researchers' attention mainly focused on the employment situations and the general impacts and fluctuations in labor market (Kaur et al., 2020; Modrego et al., 2020; Webb et al., 2020). For the economic impacts on sports (Drewes et al., 2021; 
Ehrlich et al., 2020), most of the researchers discussed the operation of football club or the leagues (Ehrlich et al., 2020). As the most basic industry, the pandemic's economic impacts on agriculture are huge. Many researchers focused on fishery (Giannakis et al., 2020; Knight et al., 2020), food (Barcaccia et al., 2020; Giudice et al., 2020; van der Ploeg, 2020; Zhang Y. et al., 2020) and dairy (Hussain et al., 2020; Uddin et al., 2020; Weersink et al., 2020), etc. Business is one of the parts that have received lots of attention, in which there have been many discussions on company's financial performance (Folger-Laronde et al., 2020; Rababah et al., 2020), the listed companies (Rababah et al., 2020; Xiong et al., 2020), the supply chain (Al-Mansour \& Al-Ajmi, 2020; Inoue \& Todo, 2020; Taqi et al., 2020), the e-commerce market (Bozhechkova et al., 2020), etc. The pandemic also has great impacts on manufacturing, and some studies discussed the issues on the auto industry (Koenig, 2020), meatpacking plants (Jansen et al., 2020), etc. Tourism is another industry that is affected by the pandemic greatly. Many of the existing studies paid attention to the problems on cruise tourism (Renaud, 2020), destination management (Gossling \& Higham, 2020), etc. For the part of energy, the economic impacts on different energy markets have been analyzed, such as alternative fuel market (Joudeh, 2020), menaces oil market (Tahir \& Batool, 2020), etc. Besides, the economic impacts of COVID-19 on higher education also received lots of research interests (Ross, 2020). When it comes to finance, as the pandemic spread, the panic mood in the market aggravated increasingly. Ali M. et al. (2020) found that although the return of gold turned negative, the volatility was still the least. Goodell (2020) presented the direct and indirect impacts of COVID-19 on financial markets and institutions, such as banking, insurance, etc. Besides, Haroon and Rizvi (2020) focused on the influence of the COVID-19-related news on the equity market. Finally, they found that the overwhelming panic generated by the news media was definitely correlated to the increasing fluctuation in the stock market. Additionally, in the sectors affected by the outbreak of the coronavirus most, the panic-laden news added to the volatility even more.

\section{The economic assessments during COVID-19}

There are also lots of research that assessed the economic situations during the pandemic. Based on the situations of people's livelihood, health and income, Bollido (2020) evaluated the economic security in San Jorge, Samar, Philippines, and they found that the livelihood of the residents in San Jorge were completely stopped. Besides, Zala et al. (2020) explored the cost-effectiveness of the hypothetical suppression policies found in the 
Imperial College COVID-19 Response Team. They concluded that the results were uncertain and conditional on the accuracy of the hypothetical imperial model projections, and it was difficult to claim that the hypothetical imperial model-projected suppression policies were obviously costineffective relative to the alternatives available. Beyond that, there have been some studies that focused on the evaluation of the economic capability to fight against COVID-19. Liu D. et al. (2020) evaluated China's resilience in fighting against COVID-19 though a time-frequency analysis, and they suggested that China might be better positioned than other emerging economies to fight against COVID-19. Referring to the fiscal measures that were taken during the 2008 crisis, Oravsky et al. (2020) divided the European countries into four parts, and they selected significant indicators though a linear panel regression to evaluate the degrees that the pandemic influenced the indicators in the selected European countries, which presented the economic risks caused by COVID-19 clearly.

\section{Other related studies}

In addition to the above, there have been some studies that analyzed the impacts of COVID-19 by combining with other theories, and some of the studies concluded the lessons on economy learned from the pandemic. From the perspective of circular economy, Weber et al. (2020) discussed the technical and economic feasibility of hand sanitizer production during the pandemic. From their study, it was considered that the production was in line with the market demand, but it was also possible that the market would slow down and the sales and revenue would be lower. Starting from the democratic theories of justice, Haagh (2020) argued that the instability of economic and public service institution in the pandemic highlighted the requirement to constitute the democratic institutions within our economy. In addition, Asfahan et al. (2020) analyzed the early trend of the indicators that affected the fatality rate in the pandemic from the points of socioeconomic and health, which was meaningful for some countries to plan strategies to fight against the pandemic. Similarly, there have been some researchers that concluded the economic lessons from COVID-19. For example, Prideaux et al. (2020) pointed out that the circular economy model not only could reduce greenhouse gases, but also provided more opportunities for the development of tourism industry. 
The studies on the measures mainly focus on three parts, i.e., the challenges analyses before proposing the measures or policies, the proposal of measures/policies, and the analyses of measures/policies. For the challenge analysis, Yezli and Khan (2020) presented the economic challenges, as well as political and religious challenges to implement the social distancing measure in the Kingdom of Saudi Arabia. Then, Sarkodie et al. (2020) found that as the spread of COVID-19 brought economic crisis in many countries/regions, many fiscal measures and monetary policies were taken, such as social assistance, social insurance and supporting labor market (Gentilini et al., 2020). From their research, the highest total economic stimulus occurs in Bahrain, the highest fiscal policy package occurs in Austria and the highest reported policy rate cut occurs in USA. Besides, McDonald (2020) presented the macroeconomic policy that helped recovery after social distancing, and found that the social distancing might leave both the stimulatory and depressive effects in post-social distancing period. Additionally, Sharma et al. (2020) firstly reviewed the related studies focusing on the economic, technological and social interventions to contain the spread of COVID-19. Then, they proposed an integrated framework of socio-economic and technological interventions of COVID-19. More comprehensively, Gong B. et al. (2020) firstly analyzed the economic impacts of COVID-19 at different levels, i.e., micro level, individual level, firm level, sector level and macro level. Then, they evaluated the policies through main methods, and found that the accuracy and transparency of the information. Finally, they also recommended some policies to reduce the economic losses. For the analysis of the measure, Kentikelenis et al. (2020) introduced the policies taken by the World Band and the International Monetary Fund firstly, and then analyzed the policies' effects. Additionally, Wuyts et al. (2020) analyzed the interaction among the circular economy principles and COVID-19 related things on healthcare and public health, which was instructive for the economic cure. In addition, Ali T. et al. (2020) started from the theory of state capacity to explain why it was unable to sustain a lockdown to stop the spread of COVID-19 in Bangladesh, a densely populated, low-income country. The gender differences also received attention. Mohapatra (2020) introduced gender differentiated economic responses in developing countries. The results not only revealed the gender differences, but also provided insights concerning gender-sensitive policies for economic recovery in COVID-19. 


\section{The influences of economy and related measures on COVID-19}

1. The economic consequences of the measures to contain COVID-19

When it comes to the consequences of the measures, most of the research focused on the lockdown policy. Some bodies of research have pointed that the application of lockdown not only helped to contain COVID-19, but also affected economy, as well as environment and people's psychology (Atalan, 2020). Bhuiyan et al. (2020) considered that the policies related to the pandemic in Bangladesh, such as spatial distancing, isolation, home quarantine, etc., would affect the sustainability of economy and result in negative emotions. In particular, the stock market was affected by the policies directly (Ayittey et al., 2020). Through utilizing the massive near-real-time data provided by Facebook, Bonaccorsi et al. (2020) confirmed the two ways that the mobility restrictions affected Italian citizens, which also presented the unprecedented challenges to conduct the policies. Besides, Newbold et al. (2020) stated that the policies-related distancing could protect citizens from being infected by the coronavirus and had deep influence on economy. The policies also affected the environment, and it was crucial to keep balance between conducting physical distancing and maintaining the development of economy. Beyond that, there have been some studies that estimated the effectiveness of the policies through establishing mathematic models. For example, Spelta et al. (2020) estimated the impacts of the interaction among the mobility restriction policies in regional production system in Italy. Then, they also used a data sets of large-scale population movements to simulate the pandemic transmission model under the lockdown policy. In a nutshell, most of the studies held the view that the healthy economy relied on the healthy people, the measures that were taken to protect people from being infected were necessary, but the extremely strict measures would put economy in a difficult situation, even in a long-term recession. Hence, it was important to find a balance point to execute the measures (Austermann et al., 2020).

\section{The economic factors that influence the transmission of COVID-19}

The outbreak of COVID-19 definitely brought huge impacts for the development of economy on many aspects. Similarly, there are also some economic factors that influence the transmission and control of the pandemic. Brock and Xepapadeas (2020) provided a modeling framework for unifying economy, climate change and COVID-19, in which they stressed that the continuous economic activities would increase the transmission of 
the pandemic. From their framework, two ways of establishing containment policies can be concluded. In the short run, the policies like social distancing were effective. In a medium or a long run, economic policies could help to reduce the epidemic and the probability of emergency. Besides, investigating that the different pandemic transmission situations in different countries, Coelho et al. (2020) studied the effects of the socio-economy, climate and transport on the increasement rate of COVID-19, and they found that the climate and socio-economy had no significant effect on it, whereas the factors related to transport had significant influence on the transmission of COVID-19 on the early age.

\section{The economy development in post-pandemic era}

In addition to the research that during the outbreak and transmission of COVID-19, there also have been some researchers who focused on the economic development during the post-pandemic era. Most of them talked about the future plans or measures to boost the development of economy in different countries/regions, or different industries, etc., in which green economy received lots of attention. For example, some researchers studied the gaps and elements that were required to build further for greening the economic recovery in India (Kedia et al., 2020). Similarly, Barbier (2020) held the view that greening the COVID-19 recovery in G20, putting a price on carbon and pollution, and removing fossil fuel subsidies, could accelerate the transition, raise revenue for necessary public investments, and reduce the overall cost of the green transition. Considering that the construction of infrastructure plays a key role in the rebirth of the economy, D' Adamo and Rosa (2020) stated that COVID-19 changed the way to think about infrastructure. In the situations where public funds and public partnerships from the private sector were needed to inject liquidity into the economic system, it was necessary to develop a long-term plan to stimulate the demand side. Also, some researchers paid attention to analyzing the world economy situation, in which Wang and Sun (2020) argued that nothing was certain in the post-COVID-19 world.

\section{Further discussions}

In this section, we mainly discuss the future research topics about the pandemic and economy from the perspectives of the time periods, i.e., the periods before the outbreak of COVID-19, during the outbreak and spread of COVID-19 and in post-pandemic era. 
The discussions about the research before the outbreak of COVID-19

In the existing studies, there have been some research that established some prediction models to predict the economic risks or economic influences, especially the fluctuations on stock market. From this point, we can try to predict and prevent the COVID-19 through lots of economic data.

Firstly, we can try to investigate some data before the outbreak of COVID-19, such as some trading data about medicine of respiratory system in some hospitals and the chemist's shops, to fetch some features linked with the pandemic. It is useful for us to understand trading features before the outbreak of the pandemic.

In addition, it is interesting to use big data technologies (Chen \& Zhang, 2014), such as blockchain (Vujicic et al., 2018), etc., to study some features of economic activities before the outbreak of the pandemic, especially some trading information on the medical equipment, daily necessities, etc. It is a good way to understand the initial reactions of people under the threat of the pandemic. Besides, knowing about the trading features of people is also helpful to prepare the corresponding resources before the outbreak of the pandemic. Additionally, the related data can also be used to predict the probability of the relapse of the pandemic, which can help us to prevent the pandemic more efficiently.

The discussions about the research during the outbreak and spread of COVID-19

In the existing studies about the time period of the pandemic's outbreak and spread, most of the studies focused on the economic impacts of the pandemic. We can try to investigate the reactions of economic indicators in different countries/regions, so that to understand the economic impacts transmission chain of the pandemic. It is not only helpful to know about the economic features in different countries or regions during the outbreak and spread of the pandemic, but also useful to understand the correlation of the different economies to improve the cooperation among them. In addition, the pandemic affects the development of different industries. Therefore, it is useful to know about the knock-on effects of the economic impacts of the pandemic, which can help us to understand the connections among different industries, and give suggestions for the industrial structure optimization.

Besides, in the existing studies, some of the researchers discussed the economic measures to fight against the pandemic. Similarly, the measures also have different impacts on different fields, as well as setting off chain effects. Hence, talking about the chain effects of the economic measures is 
a good way to assess the effectiveness of the measures, and also provide significant suggestions for eliminating the economic impacts of the pandemic.

Additionally, considering that the decision-making during the pandemic is usually under the environment with time-limits, resource limits, etc., we can take it as emergency decision-making issues. From this point of view, how to allocate the limit resources in the limit time to reach the satisfying outcome is meaningful to improve the efficiency of the decision-making during the pandemic.

\section{The discussions about the research in post-pandemic era}

In the existing studies about the research after COVID-19, many researchers talked about the future economic recovery plans. In fact, we can also pay attention to the feature analysis of the economic activities in the post-pandemic era, especially the preference changes of consumers. It is a meaningful way for private sectors to promote consumption, so that stimulating economy. Additionally, knowing about the change of investors preferences can also reflect the investment situations and the underlying movement.

In addition, the economic resources allocation in the post-pandemic era is also important for economic recovery. Hence, designing proper economic resources allocation framework based on some analyses mentioned before can help us to recognize the crucial field for development and seize the opportunity.

Besides, it is obvious that medical health plays an important role in fighting against pandemic. However, it has been ignored in many countries and regions. Therefore, how to concentrate economic power efficiently to promote the development of medical health is meaningful for the progress of human-beings.

\section{Conclusions}

In this paper, we mainly analyze the literature about the economy and COVID-19 from the perspective of bibliometrics. Firstly, the basic statistical features of the publications are presented, including the basic situations of the publications' categories, the distribution on the publication year, the distribution on different publication sources, the distribution on different countries/regions, and the basic cooperation among some countries/regions. From the analyses, it is clear that the topics related to COVID-19 and econ- 
omy have received lots of attention. Then, through the bibliometrics analyses of the citation and cooperation situations, we can find that the cooperation among the researchers shows a certain geographical distinction, but there is also the trend of global cooperation overall. Furthermore, the main themes of the existing studies are segmented to four parts, i.e., the economic impacts of COVID-19, the issues on measures, the influences of economy and measures on COVID-19, the economic development in postCOVID-19 era. From the analyses on the main themes, we also propose some future discussions from the perspectives of the time periods, which can provide meaningful suggestions for future research.

\section{References}

Afshar, A., \& Tabrizi, A. (2020). Bibliometric analysis of the 100 highly-cited articles about COVID-19. Archives of Bone and Joint Surgery, 8(6), 748-756. doi: 10.22038/abjs.2020.51846.2556.

Al-Awadhi, A. M., Alsaifi, K., Al-Awadhi, A., \& Alhammadi, S. (2020). Death and contagious infectious diseases: impact of the COVID-19 virus on stock market returns. Journal of Behavioral and Experimental Finance, 27, 100326. doi: 10.1016/j.jbef.2020.100326.

Al-Mansour, J. F., \& Al-Ajmi, S. A. (2020). Coronavirus 'COVID-19'-supply chain disruption and implications for strategy, economy, and management. Journal of Asian Finance Economics and Business, 7(9), 659-672. doi: 10.13106/jafeb.2020.vol7.no9.659.

Ali, M., Alam, N., \& Rizvi, S. A. R. (2020). Coronavirus (COVID-19)—an epidemic or pandemic for financial markets. Journal of Behavioral and Experimental Finance, 27, 100437. doi: 10.1016/j.jbef.2020.100341.

Ali, T. O., Hassan, M., \& Hossain, N. (2020). The moral and political economy of the pandemic in Bangladesh: weak states and strong societies during Covid-19. World Development, 137, 105216. doi: 10.1016/j.worlddev.2020.105216.

Anderson, R. M., Heesterbeek, H., Klinkenberg, D., \& Hollingsworth, T. D. (2020). How will country-based mitigation measures influence the course of the COVID-19 epidemic? Lancet, 395(10228), 931-934. doi: 10.1016/S01406736(20)30567-5.

Apergis, E., \& Apergis, N. (2020). Can the COVID-19 pandemic and oil prices drive the US Partisan Conflict Index? Energy Research Letters, 1(1). doi: $10.46557 / 001 \mathrm{c} .13144$.

Asfahan, S., Shahul, A., Chawla, G., Dutt, N., Niwas, R., \& Gupta, N. (2020). Early trends of socio-economic and health indicators influencing case fatality rate of COVID-19 pandemic. International Journal of Cardiopulmonary Medicine and Rehabilitation, 90(3), 451-457. doi: 10.4081/monaldi.2020.1388. 
Ashraf, B. N. (2020). Stock markets' reaction to COVID-19: cases or fatalities? Research in International Business and Finance, 54, 101249. doi: 10.1016/j.rib af.2020.101249.

Ataguba, J. E. (2020). COVID-19 pandemic, a war to be won: understanding its economic implications for Africa. Applied Health Economics and Health Policy, 18, 325-328. doi: 10.1007/s40258-020-00580-x.

Atalan, A. (2020). Is the lockdown important to prevent the COVID-19 pandemic? Effects on psychology, environment and economy-perspective. Annals of Medicine and Surgery, 56, 38-42. doi: 10.1016/j.amsu.2020.06.010.

Austermann, F., Shen, W., \& Slim, A. (2020). Governmental responses to COVID19 and its economic impact: a brief Euro-Asian comparison. Asia Europe Journal, 18(2), 211-216. doi: 10.1007/s10308-020-00577-0.

Ayittey, F. K., Ayittey, M. K., Chiwero, N. B., Kamasah, J. S., \& Dzuvor, C. (2020). Economic impacts of Wuhan 2019-nCoV on China and the world. Journal of Medical Virology, 92(5), 473-475. doi: 10.1002/jmv.25706.

Baldwin, R., \& Tomiura, E. (2020). Thinking ahead about the trade impact of COVID-19. In R. Baldwin \& B. W. di Mauro (Eds.). Economics in the time of COVID-19. London: Centre for Economic Policy Research, 59-71.

Barbier, E. B. (2020). Greening the post-pandemic recovery in the G20. Environmental and Resource Economics, 76(4), 685-703. doi: 10.1007/s10640-02000437-w.

Barcaccia, G., D'Agostino, V., Zotti, A., \& Cozzi, B. (2020). Impact of the SARSCoV-2 on the Italian agri-food sector: an analysis of the quarter of pandemic lockdown and clues for a socio-economic and territorial restart. Sustainability, 12(14), 5651. doi: 10.3390/su12145651.

Best, M. J., Aziz, K. T., McFarland, E. G., Anderson, G. F., \& Srikumaran, U. (2020). Economic implications of decreased elective orthopaedic and musculoskeletal surgery volume during the coronavirus disease 2019 pandemic. International Orthopaedics, 44(11), 2221-2228. doi: 10.1007/s00264-020-04713-8.

Bhuiyan, A. K. M. I., Sakib1, N., Pakpour, A. H., Griffiths, M. D., \& Mamun, M. A. (2020). COVID-19-related suicides in Bangladesh due to lockdown and economic factors: case study evidence from media reports. International Journal of Mental Health and Addiction. Advance online publication. doi: 10.1007/s11469-020-00307-y.

Bollido, M. E. (2020). Economic security assessment of San Jorge, Samar, Philippines, as it experiences coronavirus. Journal of Agriculture, Food Systems, and Community Development, 9(4), 131-134. doi: 10.5304/jafscd.2020.094.005.

Bonaccorsi, G., Pierri, F., Cinelli, M., Flori, A., Galeazzi, A., Porcelli, F., Schmidt, A. L., Valensise, C. M., Scala, A., Quattrociocchi, W., \& Pammolli, F. (2020). Economic and social consequences of human mobility restrictions under COVID-19. Proceeding of the National Academy of Sciences of the United States of America, 117(27). 15530-15535. doi: 10.1073/pnas.2007658117. 
Borku Uysal, B., Islamoglu, M. S., Koc, S., Karadag, M., \& Dokur, M. (2021). Most notable 100 articles of COVID-19: an altmetric study based on bibliometric analysis. Irish Journal of Medical Science. Advance online publication. doi: 10.1007/s11845-020-02460-8.

Bozhechkova, A. V., \& Evseev, A. S. (2020). Price rigidity analysis: evidence from the E-commerce market. Ekonomicheskaya Politika, 15(5), 32-59. doi: 10.182 88/1994-5124-2020-5-32-59.

Brock, W., \& Xepapadeas, A. (2020). The economy, climate change and infectious diseases: links and policy implications. Environmental and Resource Economics, 76(4), 811-824. doi: 10.1007/s10640-020-00442-z.

Casado-Aranda, L.-A., Sanchez-Fernandez, J., \& Viedma-Del-Jesus, M. I. (2021). Analysis of the scientific production of the effect of COVID-19 on the environment: a bibliometric study. Environmental Research, 193, 110416. doi: 10.1016/j.envres.2020.110416.

Chamorro-Petronacci, C., Martin Carreras-Presas, C., Sanz-Marchena, A., Rodriguez-Fernandez, M. A., Maria Suarez-Quintanilla, J., Rivas-Mundina, B., Suarez-Quintanilla, J., \& Perez-Sayans, M. (2020). Assessment of the economic and health-care impact of COVID-19 (SARS-CoV-2) on public and private dental surgeries in Spain: a pilot study. International Journal of Environmental Research and Public Health, 17(14), 5139. doi: 10.3390/ijerph17145139.

Chen, C., Dubin, R., \& Kim, M. C. (2014). Emerging trends and new developments in regenerative medicine: a scientometric update (2000-2014). Expert Opinion on Biological Therapy, 14(9), 1295-1317. doi: 10.1517/14712598.20 14.920813.

Chen, C. P., \& Zhang, C.-Y. (2014). Data-intensive applications, challenges, techniques and technologies: a survey on big data. Information Sciences, 275, 314 347. doi: 10.1016/j.ins.2014.01.015.

Chiroma, H., Ezugwu, A. E., Jauro, F., Al-Garadi, M. A., Abdullahi, I. N., \& Shuib, L. (2020). Early survey with bibliometric analysis on machine learning approaches in controlling COVID-19 outbreaks. Peerj Computer Science, 6, e313. doi: 10.7717/peerj-cs.313.

Coelho, M. T. P., Rodrigues, J. F. M., Matos, A., Medina, Scalco, P., Terribile, L. C., Vilela, B., Alexandre, J., Diniz-Filho, F., \& Dobrovolski, R. (2020). Global expansion of COVID-19 pandemic is driven by population size and airport connections. PeerJ, 8, e9708. doi: 10.7717/peerj.9708.

Cooper, I. D. (2015). Bibliometrics basics. Journal of the Medical Library Association Jmla, 103(4), 217-218. doi: 10.3163/1536-5050.103.4.013.

Costa, I. C. P., Sampaio, Rômulo Severo Souza, F. A. C. de, Dias, T. K. C., Costa, B. H. S., \& Chaves, E. de C. L. (2020). Scientific production in online journals about the new coronavirus (COVID-19): bibliometric research. Texto \& Contexto-Enfermagem, 29, e20200235. doi: 10.1590/1980-265x-tce-2020-0235.

D’Adamo, I., \& Rosa, P. (2020). How do you see infrastructure? Green energy to provide economic growth after COVID-19. Sustainability, 12(11), 4738. doi: $10.3390 / \mathrm{su} 12114738$. 
De Felice, F., \& Polimeni, A. (2020). Coronavirus disease (COVID-19): a machine learning bibliometric analysis. In Vivo, 34, 1613-1617. doi: 10.21873/inv ivo.11951.

Debata, B., Patnaik, P., \& Mishra, A. (2020). COVID-19 pandemic! It's impact on people, economy, and environment. Journal of Public Affairs, 20(4), e2372. doi: 10.1002/pa.2372.

Dehghanbanadaki, H., Seif, F., Vahidi, Y., Razi, F., Hashemi, E., Khoshmirsafa, M., \& Aazami, H. (2020). Bibliometric analysis of global scientific research on Coronavirus (COVID-19). Medical Journal of the Islamic Republic of Iran, 34(1), 354-362. doi: 10.34171/mjiri.34.51.

Drewes, M., Daumann, F., \& Follert, F. (2021). Exploring the sports economic impact of COVID-19 on professional soccer. Soccer\&Society, 22(1-2), 125137. doi: 10.1080/14660970.2020.1802256.

Ehrlich, J. A., Ghimire, S., Khraiche, M., \& Raza, M. F. (2020). COVID-19 countermeasures, sporting events, and the financial impacts to the North American leagues. Managerial Finance. Advance online publication. doi: 10.1108/MF05-2020-0275.

ElHawary, H., Salimi, A., Diab, N., \& Smith, L. (2020). Bibliometric analysis of early COVID-19 research: the top 50 cited papers. Infectious Diseases, 13, 1178633720962935. doi: 10.1177/1178633720962935.

Falagas, M. E., Pitsouni, E. I., Malietzis, G. A., \& Pappas, G. (2008). Comparison of PubMed, Scopus, Web of Science, and Google Scholar: strengths and weaknesses. Faseb Journal Official Publication of the Federation of American Societies for Experimental Biology, 22(2), 338-342. doi: 10.1096/fj.07-9492LSF.

Farooq, R. K., Rehman, S. U., Ashiq, M., Siddique, N., \& Ahmad, S. (2021). Bibliometric analysis of coronavirus disease (COVID-19) literature published in Web of Science 2019-2020. Journal of Family and Community Medicine, 28(1), 1-7. doi: 10.4103/jfcm.JFCM_332_20.

Fernandes, N. (2020). Economic effects of coronavirus outbreak (COVID-19) on the world economy. IESE Business School Working Paper, WP-1240-E. doi: 10.2139/ssrn.3557504.

Folger-Laronde, Z., Pashang, S., Feor, L., \& ElAlfy, A. (2020). ESG ratings and financial performance of exchange-traded funds during the COVID-19 pandemic. Journal of Sustainable Finance \& Investment. Advance online publication. doi: 10.1080/20430795.2020.1782814.

Furstenau, L. B., Rabaioli, B., Sott, M. K., Cossul, D., Bender, M. S., Farina, E. M. J. D. M., Filho, F. N. B., Severo, P. P., Dohan, M. S., \& Bragazzi, N. L. (2021). A bibliometric network analysis of coronavirus during the first eight months of COVID-19 in 2020. International Journal of Environmental Research and Public Health, 18(3), 952. doi: 10.3390/ijerph18030952.

Gallegos, M., Cervigni, M., Consoli, A. J., Caycho-Rodríguez, T., Polanco, F. A., Martino, P., Pecanha, V. de C., Videla, C. B., Polanco-Carrasco, R., \& Cusinato, A. M. (2020). COVID-19 in Latin America: a bibliometric analysis of scientific publications in health. Electronic Journal of General Medicine, 17(6), em261. doi: 10.29333/ejgm/8460. 
Gassling, S., Scott, D., \& Hall, C. M. (2020). Pandemics, tourism and global change: a rapid assessment of COVID-19. Journal of Sustainable Tourism. Advance online publication. doi: 10.1080/09669582.2020.1758708.

Gautam, P., Maheshwari, S., Kaushal-Deep, S. M., Bhat, A. R., \& Jaggi, C. K. (2020). COVID-19: a bibliometric analysis and insights. International Journal of Mathematical Engineering and Management Sciences, 5(6), 1156-1169. doi: 10.33889/IJMEMS.2020.5.6.088.

Gentilini, U., Almenfi, M., \& Orton, I. (2020). Social protection and jobs responses to COVID-19: a realtime review of country measures. Washington, DC: World Bank.

Giannakis, E., Hadjioannou, L., Jimenez, C., Papageorgiou, M., Karonias, A., \& Petrou, A. (2020). Economic consequences of coronavirus disease (COVID-19) on fisheries in the eastern Mediterranean (Cyprus). Sustainability, 12(22), 9406. doi: 10.3390/su12229406.

Giudice, F., Caferra, R., \& Morone, P. (2020). COVID-19, the food system and the circular economy: challenges and opportunities. Sustainability, 12(19), 7939. doi: 10.3390/su12197939.

Gong, B., Zhang, S., Yuan, L., \& Chen, K. Z. (2020). A balance act: Minimizing economic loss while controlling novel coronavirus pneumonia. Journal of Chinese Governance, 5(2), 249-268. doi: 10.1080/23812346.2020.1741940.

Gong, Y., Ma, T.-C., Xu, Y.-Y., Yang, R., Gao, L.-J., Wu, S.-H., Li, J., Yue, M.-L., Liang, H.-G., He, X., \& Yun, T. (2020). Early research on COVID-19: a bibliometric analysis. Innovation, 1(2), 100027. doi: 10.1016/j.xinn.2020.100027.

Goodell, J. W. (2020). COVID-19 and finance: agendas for future research. Finance Research Letters, 35, 101512. doi: 10.1016/j.frl.2020.101512.

Gossling, S., \& Higham, J. (2020). The low-carbon imperative: destination management under urgent climate change. Journal of Travel Research, 004728752093367. doi: 10.1177/0047287520933679.

Gupta, M., Abdelmaksoud, A., Jafferany, M., Lotti, T., Sadoughifar, R., \& Goldust, M. (2020). COVID-19 and economy. Dermatologic Therapy, 33(4), e13329. doi: $10.1111 /$ dth. 13329 .

Haagh, L. (2020). Rethinking democratic theories of justice in the economy after COVID-19. Democratic Theory, 7(2), 110-123. doi: 10.3167/dt.2020.070214.

Hall, C. M., Scott, D., \& Gössling, S. (2020). Pandemics, transformations and tourism: be careful what you wish for. Tourism Geographies, 22(3), 577-598. doi: 10.1080/14616688.2020.1759131.

Haroon, O., \& Rizvi, S. A. R. (2020). COVID-19: media coverage and financial markets behavior - a sectoral inquiry. Journal of Behavioral and Experimental Finance, 27, 100343. doi: doi: 10.1016/j.jbef.2020.100343.

Hart, O. E., \& Halden, R. U. (2020). Computational analysis of SARS-CoV2/COVID-19 surveillance by wastewater-based epidemiology locally and globally: feasibility, economy, opportunities and challenges. Science of the Total Environment, 730, 138875. doi: 10.1016/j.scitotenv.2020.138875. 
$\mathrm{Hu}, \mathrm{Y}$. (2020). Intersecting ethnic and native-migrant inequalities in the economic impact of the COVID-19 pandemic in the UK. Research in Social Stratification and Mobility, 68, 100528. doi: 10.1016/j.rssm.2020.100528.

Hussain, S., Hussain, A., Ho, J., Sparagano, O. A. E., \& Zia, U.-R. (2020). Economic and social impacts of COVID-19 on animal welfare and dairy husbandry in central Punjab, Pakistan. Frontiers in Veterinary Science, 7, 589971. doi: $10.3389 /$ fvets. 2020.589971.

Inoue, H., \& Todo, Y. (2020). The propagation of economic impacts through supply chains: the case of a mega-city lockdown to prevent the spread of COVID-19. PLoS ONE, 15(9), e0239251. doi: 10.1371/journal.pone.0239251.

Jansen, D. W., Liu, L., \& Rettenmaier, A. J. (2020). Coronavirus economics: the impact of shutting down meatpacking plants. Applied Economics Letters. Advance online publication. doi: 10.1080/13504851.2020.1808168.

Javed, B., Sarwer, A., Soto, E. B., \& Mashwani, Z.-R. (2020). Impact of SARSCoV-2 (Coronavirus) pandemic on public mental health. Froniters in Public Helth, 8, 292. doi: 10.3389/fpubh.2020.00292.

Joudeh, T. M. (2020). Alternative fuel market after Covid-19-focus on efficiency and quality. ZKA. Cement. Lime. Gypsum, 73(7-8), 44-49.

Kapecki, T. (2020). Elements of sustainable development in the context of the environmental and financial crisis and the COVID-19 pandemic. Sustainability, 12, 6188. doi: 10.3390/su12156188.

Karabag, S. F. (2020). An unprecedented global crisis! The global, regional, national, political, economic and commercial impact of the coronavirus pandemic. Journal of Applied Economics and Business Research, 10(1), 1-6.

Kaur, M., Goyal, P., \& Goyal, M. (2020). Individual, interpersonal and economic challenges of underemployment in the wake of COVID-19. Work-A Journal of Prevention Assessment \& Rehabilitation, 67(1), 21-28. doi: 10.3233/WOR203249.

Kedia, S., Pandey, R., \& Sinha, R. (2020). Shaping the post-COVID-19 development paradigm in India: some imperatives for greening the economic recovery. Millennial Asia, 11(3), 268-298. doi: 10.1177/0976399620958509.

Kentikelenis, A., Gabor, D., Ortiz, I., Stubbs, T., Mckee, M., \& Stuckler, D. (2020). Softening the blow of the pandemic: will the International Monetary Fund and World Bank make things worse? Lancet Global Health, 8(6), E758-E759. doi: 10.1016/S2214-109X(20)30135-2.

Knight, C. J., Burnham, T. L. U., Mansfield, E. J., Crowder, L. B., \& Micheli, F. (2020). COVID-19 reveals vulnerability of small-scale fisheries to global market systems. Lancet Planetary Health, 4(6), e219. doi: 10.1016/S25425196(20)30128-5.

Koenig, B. (2020). Trade group: COVID-19 pressing auto industry hard. Manufacturing Engineering, 164(5), 24.

Korzeb, Z., \& Niedziolka, P. (2020). Resistance of commercial banks to the crisis caused by the COVID-19 pandemic: the case of Poland. Equilibrium. Quarterly Journal of Economics and Economic Policy, 15(2), 205-234. doi: 10.24136 /eq.2020.010. 
Kuc-Czarnecka, M. (2020). COVID-19 and digital deprivation in Poland. Oeconomia Copernicana, 11(3), 415-431. doi: 10.24136/oc.2020.017.

Kufel, T. (2020). ARIMA-based forecasting of the dynamics of confirmed Covid19 cases for selected European countries. Equilibrium. Quarterly Journal of Economics and Economic Policy, 15(2), 181-204. doi: 10.24136/eq.2020.009.

Leslie, S. A., \& Chris, R. (2013). Web of Science, Scopus and Google Scholar: A content comprehensiveness comparison. Electronic Library, 31(6), 727-744. doi: 10.1108/EL-12-2011-0174.

Liu, D., Sun, W., \& Zhang, X. (2020). Is the Chinese economy well positioned to fight the COVID-19 pandemic? The financial cycle perspective. Emerging Markets Finance and Trade, 56(10), 2259-2276. doi: 10.1080/1540496X.20 20.1787152.

Liu, H., Manzoor, A., Wang, C., Zhang, L., \& Manzoor, Z. (2020). The COVID-19 outbreak and affected countries stock markets response. International Journal of Environmental Research and Public Health, 17(8), 2800. doi: 10.3390/Ij erph17082800.

Lou, J., Tian, S.-J., Niu, S.-M., Kang, X.-Q., Lian, H.-X., Zhang, L.-X., \& Zhang, J.-J. (2020). Coronavirus disease 2019: a bibliometric analysis and review. European Review for Medical and PharmacologicalLou Sciences, 24(6), 34113421.

Maalouf, F. T., Mdawar, B., Meho, Lokman, I., \& Akl, E. A. (2021). Mental health research in response to the COVID-19, Ebola, and H1N1 outbreaks: a comparative bibliometric analysis. Journal of Psychiatric Research, 132, 198-206. doi: 10.1016/j.jpsychires.2020.10.018.

Mamun, M. A., \& Ullah, I. (2020). COVID-19 suicides in Pakistan, dying off not COVID-19 fear but poverty? - The forthcoming economic challenges for a developing country. Brain Behavior and Immunity, 87, 163-166. doi: 10.1016/j.b bi.2020.05.028.

Mao, X., Guo, L., Fu, P., \& Xiang, C. (2020). The status and trends of coronavirus research: a global bibliometric and visualized analysis. Medicine, 99(22), e20137. doi: 10.1097/MD.0000000000020137.

McDonald, I. M. (2020). Macroeconomic policy to aid recovery after social distancing for COVID-19. Australian Economic Review, 53(3), 415-428. doi: 10.1111/1467-8462.12387.

McKee, M., \& Stuckler, D. (2020). If the world fails to protect the economy, COVID-19 will damage health not just now but also in the future. Nature Medicine, 26, 640-642. doi: doi.org/10.1038/s41591-020-0863-y.

McKibbin, W. J., \& Fernando, R. (2020). The global macroeconomic impacts of COVID-19: Seven scenarios. CAMA Working Paper, 19/2020. doi: 10.2139/ssr n.3547729.

Modrego, F., Canales, A., \& Bahamonde, H. (2020). Employment effects of COVID-19 across Chilean regions: an application of the translog cost function. Regional Science Policy and Pratice, 12(6), 1151-1167. doi: 10.1111/rsp3.1 2337. 
Mohadab, M. El, Bouikhalene, B., \& Safi, S. (2020). Bibliometric method for mapping the state of the art of scientific production in Covid-19. Chaos, Solitons \& Fractals, 139, 110052. doi: 10.1016/j.chaos.2020.110052.

Mohapatra, S. (2020). Gender differentiated economic responses to crises in developing countries insights for COVID-19 recovery policies. Review of Economics of the Household. Advance online publication. doi: 10.1007/s11150-02009512-z.

Moore, C., \& Kolencik, J. (2020). Acute depression, extreme anxiety, and prolonged stress among COVID-19 frontline healthcare workers. Psychosociological Issues in Human Resource Management, 8(1), 55-60. doi: 10.22381/PIHR M8120209.

Newbold, S. C., Finnoff, D., Thunström, L., Ashworth, M., \& Shogren, J. F. (2020). Effects of physical distancing to control COVID-19 on public health, the economy, and the environment. Environmental and Resource Economics, 76, 705-729. doi: 10.1007/s10640-020-00440-1.

Nicola, M., Alsafib, Z., Sohrabic, C., Kerwand, A., Al-Jabird, A., Iosifidisc, C., Aghae, M., \& Aghaf, R. (2020). The socio-economic implications of the coronavirus pandemic (COVID-19): a review. International Journal of Surgery, 78, 185-193. doi: 10.1016/j.ijsu.2020.04.018.

Noy, I., Doan, N., Ferrarini, B., \& Park, D. (2020). Measuring the economic risk of COVID-19. Global Policy, 11(4). doi: 10.1111/1758-5899.12851.

Oh, J., \& Kim, A. (2020). A bibliometric analysis of COVID-19 research published in nursing journals. Science Editing, 7(2), 118-124. doi: 10.6087/kcse.205.

Oliveira, E. M. N. de, Carvalho, A. R. B. de, Silva, J., de Sousa Neto, A., de, Moura, M. E. B., \& de Freitas, D. R. J. (2021). Analysis of scientific production on the new coronavirus (COVID-19): a bibliometric analysis. Sao Paulo Medical Journal. Advance online publication. doi: 10.1590/1516-3180.2 020.0449.R1.01102020.

Oravsky, R., Toth, P., \& Banociova, A. (2020). The ability of selected European countries to face the impending economic crisis caused by COVID-19 in the context of the global economic crisis of 2008. Journal of Risk and Financial Management, 13, 179. doi: 10.3390/jrfm13080179.

Patel, N. (2020). Impact on dental economics and dental healthcare utilization in COVID-19: an exploratory study. Journal of Advanced Oral Research, 11(2), 128-136. doi: 10.1177/2320206820941365.

Phan, D. H. B., \& Narayan, P. K. (2020). Country responses and the reaction of the stock market to COVID-19-a preliminary exposition. Emerging Markets Finance and Trade, 56(10), 2138-2150. doi: 10.1080/1540496X.2020.1784719.

Popescu Ljungholm, D., \& Olah, M. L. (2020). Mental health consequences of the COVID-19 crisis on frontline healthcare professionals: psychological impairments as a result of work-related stress. Psychosociological Issues in Human Resource Management, 8(1), 31-36. doi: 10.22381/PIHRM8120205.

Porsse, A. A., Souza, K. B. de, Carvalho, T. S., \& Vale, V. A. (2020). The economic impacts of COVID-19 in Brazil based on an interregional CGE approach. Regional Science Policy \& Practice, 12, 1105-1121. doi: 10.1111/rsp3.12354. 
Prideaux, B., Thompson, M., \& Pabel, A. (2020). Lessons from COVID-19 can prepare global tourism for the economic transformation needed to combat climate change. Tourism Geographies, 22(3), 667-678. doi: 10.1080/1461668 8.2020.1762117.

Qiu, Y., Chen, X., \& Shi, W. (2020). Impacts of social and economic factors on the transmission of coronavirus disease 2019 (COVID-19) in China. Journal of Population Economics, 33(4), 1127-1172. doi: 10.1007/s00148-020-00778-2.

Rababah, A., Al-Haddad, L., Sial, M. S., Chunmei, Z., \& Cherian, J. (2020). Analyzing the effects ofCOVID-19 pandemic on the financial performance of Chinese listed companies. Journal of Public Affairs, 20(4), e2440. doi: 10.1002/ pa.2440.

Raju, V. N., \& Patil, S. B. (2020). Indian publications on SARS-CoV-2: a bibliometric study of WHO. Diabetes \& Metabolic Syndrome: Clinical Research \& Reviews, 14, 1171-1178. doi: 10.1016/j.dsx.2020.07.007.

Ramelli, S., \& Wagner, A. F. (2020). Feverish stock price reactions to COVID-19. Review of Corporate Finance Studies, 9(3), 622-655. doi: 10.1093/rcfs/cf aa012.

Renaud, L. (2020). Reconsidering global mobility -distancing from mass cruise tourism in the aftermath of COVID-19. Tourism Geographies, 22(3), 679-689. doi: 10.1080/14616688.2020.1762116.

Rodrigues, M., Franco, M., \& Silva, R. (2020). COVID-19 and disruption in management and education academics: bibliometric mapping and analysis. Sustainability, 12(8), 7362. doi: 10.3390/su12187362.

Ross, J. (2020). Economic ramifications of the COVID-19 pandemic for higher education: a circuit breaker in Australian universities' business model? Higher Education Research \& Development, 39(7), 1351-1356. doi: 10.1080/07294 360.2020.1825350.

Sarkodie, S. A., \& Owusu, P. A. (2020). Global assessment of environment, health and economic impact of the novel coronavirus (COVID-19). Environment, Development and Sustainability. Advance online publication. doi: 10.1007/s10668 -020-00801-2.

Sharif, A., Aloui, C., \& Yarovaya, L. (2020). COVID-19 pandemic, oil prices, stock market, geopolitical risk and policy uncertainty nexus in the US economy: fresh evidence from the wavelet-based approach. International Review of Financial Analysis, 70, 101496. doi: doi: 10.1016/j.irfa.2020.101496.

Sharma, R. K., Srivastava, A., Vinay, M., \& Sethi, R. (2020). An integrated framework of socio-economic and technological interventions for COVID-19 in different economies. Journal of Statistics and Management Systems. Advance online publication. doi: 10.1080/09720510.2020.1838062.

Spelta, A., Flori, A., Pierri, F., Bonaccorsi, G., \& Pammolli, F. (2020). After the lockdown: simulating mobility, public health and economic recovery scenarios. Scientific Reports, 10(1), 16950. doi: 10.1038/s41598-020-73949-6.

Suryahadi, A., Izzati, R. A., \& Suryadarma, D. (2020). Estimating the impact of COVID-19 outbreak on poverty. Bulletin of Indonesian Economic Studies. Advance online publication. doi: 10.1080/00074918.2020.1779390. 
Tahir, M. B., \& Batool, A. (2020). COVID-19: healthy environmental impact for public safety and menaces oil market. Science of the Total Environment, 740, 140054. doi: 10.1016/j.scitotenv.2020.140054.

Taqi, H. M. M., Ahmed, H. N., Paul, S., Garshasbi, M., Ali, S. M., \& Paul, S. K. (2020). Strategies to manage the impacts of the COVID-19 pandemic in the supply chain: implications for improving economic and social sustainability. Sustainability, 12(22), 9483. doi: 10.3390/su12229483.

Uddin, M. M., Akter, A., Khaleduzzaman, A. B. M., Sultana, M. N., \& Hemme, T. (2020). Application of the farm simulation model approach on economic loss estimation due to coronavirus (COVID-19) in Bangladesh dairy farmsstrategies, options, and way forward. Tropical Animal Health and Production, 53(1), 33. doi: 10.1007/s11250-020-02471-8.

van der Ploeg, J. D. (2020). From biomedical to politico-economic crisis: the food system in times of Covid-19. Journal of Peasant Studies, 47(5), 944-972. doi: 10.1080/03066150.2020.1794843.

Verma, S., \& Gustafsson, A. (2020). Investigating the emerging COVID-19 research trends in the field of business and management: a bibliometric analysis approach. Journal of Business Research, 118, 253-261. doi: 10.1016/j.jbus res.2020.06.057.

Vujicic, D., Jagodic, D., \& Randic, S. (2018). Blockchain technology, bitcoin, and Ethereum: a brief overview. In 17th international symposium INFOTEHJAHORINA (INFOTEH), 1-6. doi: 10.1109/INFOTEH.2018.8345547.

Wang, X., Xu, Z., Su, S.-F., \& Zhou, W. (2021). A comprehensive bibliometric analysis of uncertain group decision making from 1980 to 2019. Information Sciences, 547, 328-353. doi: 10.1016/j.ins.2020.08.036.

Wang, Z., \& Sun, Z. (2020). From globalization to regionalization: the United States, China, and the post-Covid-19 world economic order. Journal of Chinese Political Science. Advance online publication. doi: 10.1007/s11366-02009706-3.

Webb, A., McQuaid, R., \& Rand, S. (2020). Employment in the informal economy: implications of the COVID-19 pandemic. International Journal of Sociology and Social Policy, 40(9-10), 1005-1019. doi: 10.1108/IJSSP-08-2020-0371.

Weber, C. T., Ranzan, L., Liesegang, L. L. M., Trierweiler, L. F., \& Trierweiler, J. O. (2020). A circular economy model for ethanol and alcohol-based hand sanitizer from sweet potato waste in the context of COVID-19. Brazilian Journal of Operations \& Production Management, 17(3), e20201025. doi: 10.14488/1 0.14488/BJOPM.2020.028.

Weersink, A., von Massow, M., \& McDougall, B. (2020). Economic thoughts on the potential implications of COVID-19 on the Canadian dairy and poultry sectors. Canadian Journal of Agricultural Economics-Revue Canadienne D Agroeconomie, 68(2), 195-200. doi: 10.1111/cjag.12240.

Williams, T. (2020). The impact of COVID-19. Journal of Perioperative Practice, 30(5), 114-115. doi: 10.1177/1750458920919642. 
Wuyts, W., Marin, J., Brusselaers, J., \& Vrancken, K. (2020). Circular economy as a COVID-19 cure? Resources, Conservation \& Recycling, 162, 105016. doi: 10.1016/j.resconrec.2020.105016.

Xiong, H., Wu, Z., \& Zhang, J. (2020). Which firm-specific characteristics affect the market reaction of Chinese listed companies to the COVID-19 pandemic? Emerging Markets Finance and Trade, 56(10), 2231-2242. doi: 10.1080/1540 496X.2020.1787151.

Yang, F., Zhang, S., Wang, Q., Zhang, Q., Han, J., Wang, L., Wu, X., \& Xue, F. (2020). Analysis of the global situation of COVID-19 research based on bibliometrics. Social Science Electronic Publishing, 8(1). doi: 10.2139/ssrn.360 5135.

Yezli, S., \& Khan, A. (2020). COVID-19 social distancing in the Kingdom of Saudi Arabia: bold measures in the face of political, economic, social and religious challenges. Travel Medicine and Infectious Disease, 37, 101692. doi: 10.1016/ j.tmaid.2020.101692.

Yu, D., Xu, Z., Pedrycz, W., \& Wang, X. (2017). Information sciences 1968-2016: a retrospective analysis with text mining and bibliometric. Information Sciences, 418-419, 619-634. doi: 10.1016/j.ins.2017.08.031.

Yu, Y., Li, Y., Zhang, Z., Gu, Z., Zhong, H., Zha, Q., Yang, L., Zhu, C., \& Chen, E. (2020). A bibliometric analysis using VOSviewer of publications on COVID19. Annals of Translational Medicine, 8(13). doi: 10.21037/atm-20-4235.

Yue, X.-G., Shao, X.-F., Li, R. Y. M., Crabbe, M. J. C., Mi, L., Hu, S., Baker, J. S., Liu, L., \& Dong, K. (2020). Risk prediction and assessment: duration, infections, and death toll of the COVID-19 and its impact on China's economy. Journal of Risk and Financial Management, 13(4), 66. doi: 10.3390/jrfm130 40066.

Zala, D., Mosweu, I., Critchlow, S., Romeo, R., \& McCrone, P. (2020). Costing the COVID-19 pandemic: an exploratory economic evaluation of hypothetical suppression policy in the United Kingdom. Value in Health, 23(11), 1432 1437. doi: 10.1016/j.jval.2020.07.001.

Zhang, D., Hu, M., \& Ji, Q. (2020). Financial markets under the global pandemic of COVID-19. Finance Research Letters, 36, 101528. doi: 10.1016/j.frl.202 0.101528 .

Zhang, J. (2020). Five basic insights into the economic impact of the COVID-19 outbreak. Froniter of Economics in China, 15(2), 167-178. doi: 10.3868/s060011-020-0008-8.

Zhang, Y., Diao, X., Chen, K. Z., Robinson, S., \& Fan, S. (2020). Impact of COVID-19 on China's macroeconomy and agri-food system-an economy-wide multiplier model analysis. China Agricultural Economic Review, 12(3), 387407. doi: 10.1108/CAER-04-2020-0063.

Zinecker, M., Doubravsky, K., Balcerzak, A. P., Pietrzak, M. B., \& Dohnal, M. (2021). The Covid-19 disease and policy response to mitigate the economic impact in the EU. Technological and Economic Development of Economy, 27(3), 742-762. doi: 10.3846/tede.2021.14585. 
Zyoud, Saed H., \& Al-Jabi, S. W. (2020). Mapping the situation of research on coronavirus disease-19 (COVID-19): a preliminary bibliometric analysis during the early stage of the outbreak. BMC Infectious Diseases, 20(1), 561. doi: 10.1186/s12879-020-05293-z.

Zyoud, S. H., \& Zyoud, A. H. (2020). Coronavirus disease-19 in environmental fields: a bibliometric and visualization mapping analysis. Environment, Development and Sustainability, Advance online publication. doi: 10.1007/s10668020-01004-5. 


\section{Annex}

Table 1. The distribution on different publication sources

\begin{tabular}{lccccc}
\hline Sources & TP & \% of 601 & TC & TC/TP & H-index \\
\hline Sustainability & 16 & 2.66 & 22 & 1.38 & 3 \\
Journal of Public Affairs & 14 & 2.33 & 23 & 1.64 & 3 \\
Survey Research Methods & 12 & 2.00 & 3 & 0.25 & 1 \\
Finance Research Letters & 11 & 1.83 & 169 & 15.36 & 5 \\
Emerging Markets Finance and Trade & 10 & 1.66 & 59 & 5.9 & 5 \\
Environmental Resource Economics & 9 & 1.50 & 23 & 2.56 & 3 \\
Frontiers in Psychology & 7 & 1.17 & 11 & 1.57 & 2 \\
Tourism Geographies & 7 & 1.17 & 146 & 20.86 & 6 \\
Applied Economics Letters & 6 & 1.00 & 7 & 1.117 & 2 \\
International Journal of Environmental & 6 & 1.00 & 36 & 6 & 3 \\
Research and Public Health & & 1.00 & 18 & 3 & 3 \\
Journal of Asian Finance Economics and & 6 & & & & \\
Business & & & & & \\
\hline
\end{tabular}

Table 2. The most 10 prolific countries/regions

\begin{tabular}{lccccc}
\hline Countries/Regions & TP & \% of 601 & TC & TC/TP & H-index \\
\hline USA & 123 & 20.50 & 447 & 3.63 & 10 \\
China & 69 & 11.48 & 341 & 4.94 & 9 \\
England & 61 & 10.15 & 705 & 11.56 & 8 \\
Italy & 40 & 6.66 & 196 & 4.90 & 7 \\
India & 36 & 5.99 & 79 & 2.19 & 5 \\
Germany & 35 & 5.82 & 51 & 1.46 & 3 \\
Australia & 32 & 5.32 & 162 & 5.06 & 7 \\
Russia & 27 & 4.49 & 10 & 0.37 & 2 \\
Canada & 21 & 3.49 & 128 & 6.10 & 6 \\
Spain & 20 & 3.33 & 24 & 1.20 & 2 \\
\hline
\end{tabular}


Table 3. The basic cooperation situations of the top-10 countries/regions

\begin{tabular}{lccccc}
\hline Countries/Regions & NCP & \% of TP & CTCP & CTCP/NCP & NCC \\
\hline USA & 44 & 35.77 & 176 & 4.00 & 32 \\
China & 31 & 44.93 & 142 & 4.58 & 31 \\
England & 36 & 59.02 & 271 & 7.53 & 36 \\
Italy & 17 & 42.50 & 108 & 6.35 & 15 \\
India & 7 & 19.44 & 36 & 5.14 & 16 \\
Germany & 20 & 57.14 & 45 & 2.25 & 23 \\
Australia & 16 & 50.00 & 90 & 5.63 & 22 \\
Russia & 7 & 25.93 & 4 & 0.57 & 9 \\
Canada & 8 & 38.10 & 87 & 10.88 & 15 \\
Spain & 11 & 55.00 & 22 & 2.00 & 19 \\
\hline
\end{tabular}

Table 4. The top-10 cited publications

\begin{tabular}{|c|c|c|c|}
\hline Title & Source Publication & $\begin{array}{c}\text { Publication } \\
\text { year }\end{array}$ & $\begin{array}{c}\text { Total } \\
\text { Citation }\end{array}$ \\
\hline $\begin{array}{l}\text { The socio-economic implications of the } \\
\text { coronavirus pandemic (COVID-19): A } \\
\text { review (Nicola et al., 2020) }\end{array}$ & $\begin{array}{l}\text { International Journal } \\
\text { of Surgery }\end{array}$ & 2020 & 368 \\
\hline $\begin{array}{l}\text { If the world fails to protect the economy, } \\
\text { COVID-19 will damage health not just now } \\
\text { but also in the future (McKee \& Stuckler, } \\
2020 \text { ) }\end{array}$ & Nature Medicine & 2020 & 65 \\
\hline $\begin{array}{l}\text { Financial markets under the global pandemic } \\
\text { of COVID-19 (D. Zhang et al., 2020) }\end{array}$ & $\begin{array}{l}\text { Finance } \quad \text { Research } \\
\text { Letters }\end{array}$ & 2020 & 62 \\
\hline $\begin{array}{l}\text { Economic impacts of Wuhan 2019-nCoV on } \\
\text { China and the world (Ayittey et al., 2020) }\end{array}$ & $\begin{array}{l}\text { Journal of Medical } \\
\text { Virology }\end{array}$ & 2020 & 61 \\
\hline $\begin{array}{l}\text { COVID-19 and finance: Agendas for future } \\
\text { research (Goodell, 2020) }\end{array}$ & $\begin{array}{l}\text { Finance } \quad \text { Research } \\
\text { Letters }\end{array}$ & 2020 & 56 \\
\hline $\begin{array}{l}\text { Death and contagious infectious diseases: } \\
\text { Impact of the COVID-19 virus on stock } \\
\text { market returns (Al-Awadhi et al., 2020) }\end{array}$ & $\begin{array}{l}\text { Journal of Behavioral } \\
\text { and } \quad \text { Experimental } \\
\text { Finance }\end{array}$ & 2020 & 54 \\
\hline $\begin{array}{l}\text { COVID-19 pandemic, oil prices, stock } \\
\text { market, geopolitical risk and policy } \\
\text { uncertainty nexus in the US economy: Fresh } \\
\text { evidence from the wavelet-based approach } \\
\text { (Sharif et al., 2020) }\end{array}$ & $\begin{array}{l}\text { International Review } \\
\text { of Financial Analysis }\end{array}$ & 2020 & 49 \\
\hline $\begin{array}{l}\text { Pandemics, transformations and tourism: be } \\
\text { careful what you wish for (Hall } \text { et al., 2020) }\end{array}$ & Tourism Geographies & 2020 & 47 \\
\hline $\begin{array}{l}\text { Computational analysis of SARS-CoV- } \\
2 / \text { COVID-19 surveillance by wastewater- } \\
\text { based epidemiology locally and globally: } \\
\text { Feasibility, economy, opportunities and } \\
\text { challenges (Hart \& Halden, 2020) }\end{array}$ & $\begin{array}{l}\text { Science of the Total } \\
\text { Environment }\end{array}$ & 2020 & 45 \\
\hline $\begin{array}{l}\text { Impacts of social and economic factors on } \\
\text { the transmission of coronavirus disease } 2019 \\
\text { (COVID-19) in China (Qiu et al., 2020) }\end{array}$ & $\begin{array}{l}\text { Journal of Population } \\
\text { Economics }\end{array}$ & 2020 & 44 \\
\hline
\end{tabular}


Table 5. The top-12 cited references

\begin{tabular}{|c|c|c|c|c|}
\hline Document & Cluster & Links & Total link strength & Citations \\
\hline $\begin{array}{l}\text { Death and contagious infectious } \\
\text { diseases: Impact of the COVID-19 virus } \\
\text { on stock market returns (Al-Awadhi et } \\
\text { al., 2020) }\end{array}$ & 5 & 65 & 146 & 21 \\
\hline $\begin{array}{l}\text { Financial markets under the global } \\
\text { pandemic of COVID-19 (Zhang D. et al., } \\
\text { 2020a) }\end{array}$ & 5 & 66 & 145 & 19 \\
\hline $\begin{array}{l}\text { COVID-19 and finance: Agendas for } \\
\text { future research (Goodell, 2020) }\end{array}$ & 2 & 49 & 93 & 17 \\
\hline $\begin{array}{l}\text { The global macroeconomic impacts of } \\
\text { COVID-19: seven scenarios (McKibbin } \\
\& \text { Fernando, 2020) }\end{array}$ & 4 & 61 & 78 & 17 \\
\hline $\begin{array}{l}\text { The socio-economic implications of the } \\
\text { coronavirus and COVID-19 pandemic: A } \\
\text { review (Nicola } \text { et al., 2020) }\end{array}$ & 4 & 54 & 71 & 16 \\
\hline $\begin{array}{l}\text { Coronavirus (COVID-19)-An epidemic } \\
\text { or pandemic for financial markets (Ali } \\
\text { M. et al., 2020) }\end{array}$ & 6 & 52 & 140 & 14 \\
\hline $\begin{array}{l}\text { Thinking ahead about the trade impact of } \\
\text { COVID-19 (Baldwin \& Tomiura, 2020) }\end{array}$ & 1 & 43 & 53 & 14 \\
\hline $\begin{array}{l}\text { Economic effects of coronavirus } \\
\text { outbreak (COVID-19) on the world } \\
\text { economy (Fernandes, 2020) }\end{array}$ & 4 & 40 & 49 & 14 \\
\hline $\begin{array}{l}\text { How will country-based mitigation } \\
\text { measures influence the course of the } \\
\text { COVID-19 epidemic? (Anderson et al., } \\
\text { 2020) }\end{array}$ & 1 & 47 & 57 & 13 \\
\hline $\begin{array}{l}\text { Can the COVID- } 19 \text { pandemic and oil } \\
\text { prices drive the US partisan conflict } \\
\text { index (Apergis \& Apergis, 2020) }\end{array}$ & 6 & 34 & 115 & 13 \\
\hline $\begin{array}{l}\text { Pandemics, tourism and global change: A } \\
\text { rapid assessment of COVID-19 } \\
\text { (Gassling } \text { et al., 2020) }\end{array}$ & 1 & 38 & 46 & 13 \\
\hline $\begin{array}{l}\text { COVID-19 pandemic, oil prices, stock } \\
\text { market, geopolitical risk and policy } \\
\text { uncertainty nexus in the US economy: } \\
\text { Fresh evidence from the wavelet-based } \\
\text { approach (Sharif } \text { et al., 2020) }\end{array}$ & 2 & 54 & 85 & 13 \\
\hline
\end{tabular}

Table 6. The basic cooperation indicators of the top-10 prolific countries/regions

\begin{tabular}{lccccc}
\hline Countries/regions & Cluster & Links & Total link strength & Documents & Citations \\
\hline USA & 6 & 35 & 84 & 123 & 447 \\
China & 5 & 31 & 57 & 69 & 341 \\
England & 10 & 36 & 81 & 61 & 705 \\
Italy & 2 & 14 & 33 & 40 & 196 \\
India & 3 & 18 & 19 & 36 & 79 \\
\hline
\end{tabular}


Table 6. Continued

\begin{tabular}{lccccc}
\hline Countries/regions & Cluster & Links & Total link strength & Documents & Citations \\
\hline Germany & 6 & 23 & 40 & 35 & 51 \\
Australia & 8 & 22 & 39 & 32 & 162 \\
Russia & 2 & 9 & 13 & 27 & 10 \\
Canada & 9 & 15 & 18 & 21 & 128 \\
Spain & 2 & 19 & 31 & 20 & 24 \\
\hline
\end{tabular}

Table 7. The basic cooperation indicators of the top-11 prolific institutions in the largest cooperation sub-network

\begin{tabular}{|c|c|c|c|c|c|}
\hline Institution & Cluster & Links & $\begin{array}{l}\text { Total link } \\
\text { strength }\end{array}$ & Documents & Citations \\
\hline University of Oxford & 14 & 22 & 22 & 9 & 13 \\
\hline $\begin{array}{l}\text { London School of Hygiene \& } \\
\text { Tropical Medicine }\end{array}$ & 6 & 17 & 18 & 6 & 83 \\
\hline University of Sydney & 8 & 34 & 39 & 6 & 30 \\
\hline Columbia University & 3 & 12 & 15 & 5 & 8 \\
\hline Johns Hopkins University & 11 & 11 & 12 & 5 & 6 \\
\hline Bocconi University & 3 & 11 & 13 & 4 & 73 \\
\hline Boston University & 3 & 11 & 14 & 4 & 3 \\
\hline Duke University & 9 & 15 & 15 & 4 & 18 \\
\hline Kings College of London & 4 & 10 & 10 & 4 & 371 \\
\hline $\begin{array}{l}\text { London School of Economics and } \\
\text { Political Science }\end{array}$ & 4 & 8 & 8 & 4 & 21 \\
\hline Trinity College Dublin & 6 & 21 & 21 & 4 & 3 \\
\hline
\end{tabular}

Table 8. The basic cooperation indicators of the top-10 prolific authors in the largest author-level cooperation sub-network

\begin{tabular}{lccccc}
\hline Author & Cluster & Links & Total link strength & Documents & Citations \\
\hline Mckee Martin & 2 & 11 & 12 & 4 & 82 \\
Gallagher Kevin P. & 1 & 7 & 10 & 3 & 3 \\
Anderson Michael & 4 & 3 & 4 & 2 & 20 \\
Kentikelenis Alexander & 3 & 8 & 9 & 2 & 8 \\
Kring William N. & 1 & 7 & 8 & 2 & 3 \\
Mossialos Elias & 4 & 3 & 4 & 2 & 20 \\
Ocampo Jose Antonio & 1 & 4 & 6 & 2 & 0 \\
\hline
\end{tabular}


Table 8. Continued

\begin{tabular}{lccccc}
\hline Author & Cluster & Links & Total link strength & Documents & Citations \\
\hline Stubbs Thomas & 3 & 8 & 9 & 2 & 8 \\
Stuckler David & 3 & 5 & 6 & 2 & 70 \\
Volz Ulrich & 1 & 4 & 6 & 2 & 0 \\
\hline
\end{tabular}

Table 9. The basic indicators of the keywords with more than 16 occurrences

\begin{tabular}{lcccc}
\hline Keywords & Cluster & Links & Total link strength & Occurrences \\
\hline covid-19 & 3 & 70 & 465 & 313 \\
pandemic & 5 & 51 & 132 & 58 \\
impact & 1 & 43 & 104 & 34 \\
economy & 5 & 26 & 53 & 20 \\
risk & 1 & 31 & 57 & 20 \\
china & 3 & 22 & 42 & 18 \\
crisis & 2 & 31 & 53 & 18 \\
economic & 2 & 24 & 38 & 17 \\
growth & 2 & 28 & 45 & 17 \\
growth & 5 & 26 & 52 & 17 \\
health & 3 & 18 & 34 & 17 \\
stock market & & & & \\
\hline
\end{tabular}

Table 10. The basic indicators of the top-10 terms on the occurrence

\begin{tabular}{lcccc}
\hline Terms & Cluster & Links & Total link strength & Occurrences \\
\hline covid-19 & 5 & 252 & 9242 & 485 \\
pandemic & 5 & 252 & 5857 & 275 \\
impact & 3 & 250 & 4517 & 191 \\
economy & 4 & 249 & 3841 & 188 \\
crisis & 2 & 251 & 3212 & 135 \\
study & 3 & 250 & 3740 & 135 \\
country & 3 & 250 & 3369 & 125 \\
effect & 3 & 249 & 2972 & 113 \\
model & 4 & 249 & 2761 & 111 \\
paper & 2 & 249 & 2487 & 100 \\
\hline
\end{tabular}


Figure 1. Retrieving methods

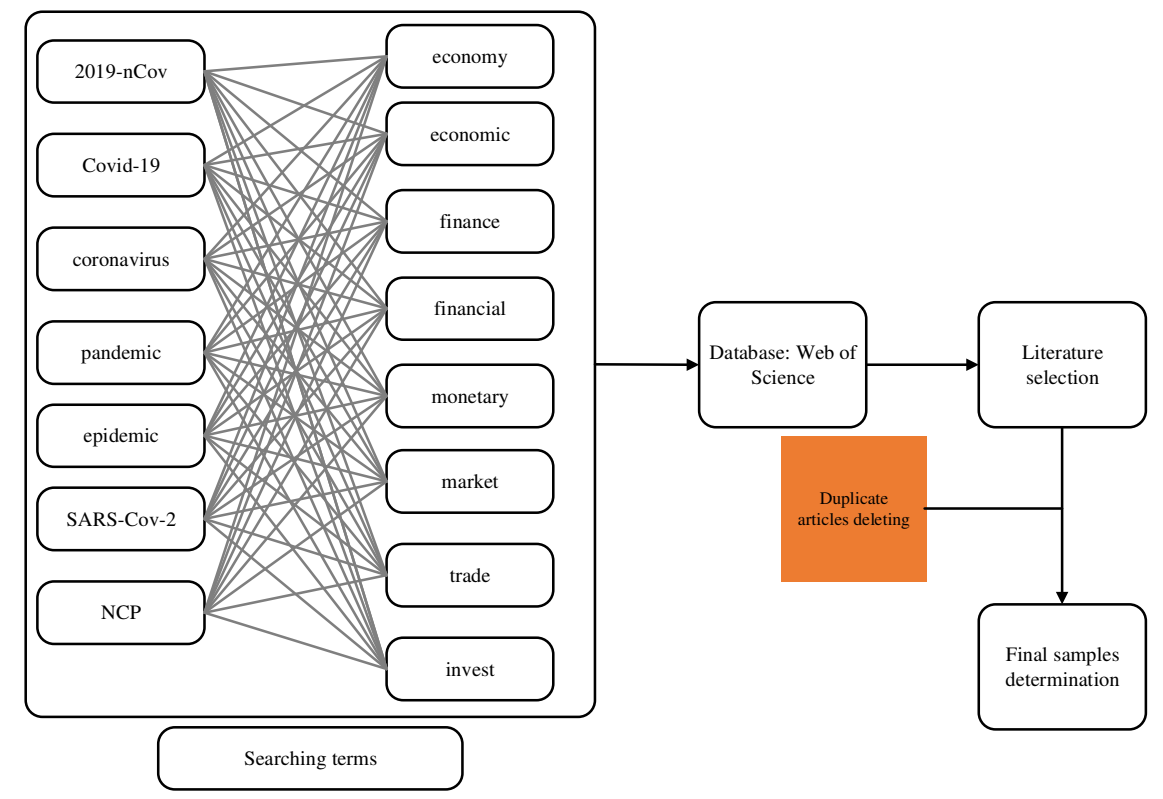

Figure 2. The distribution on different years

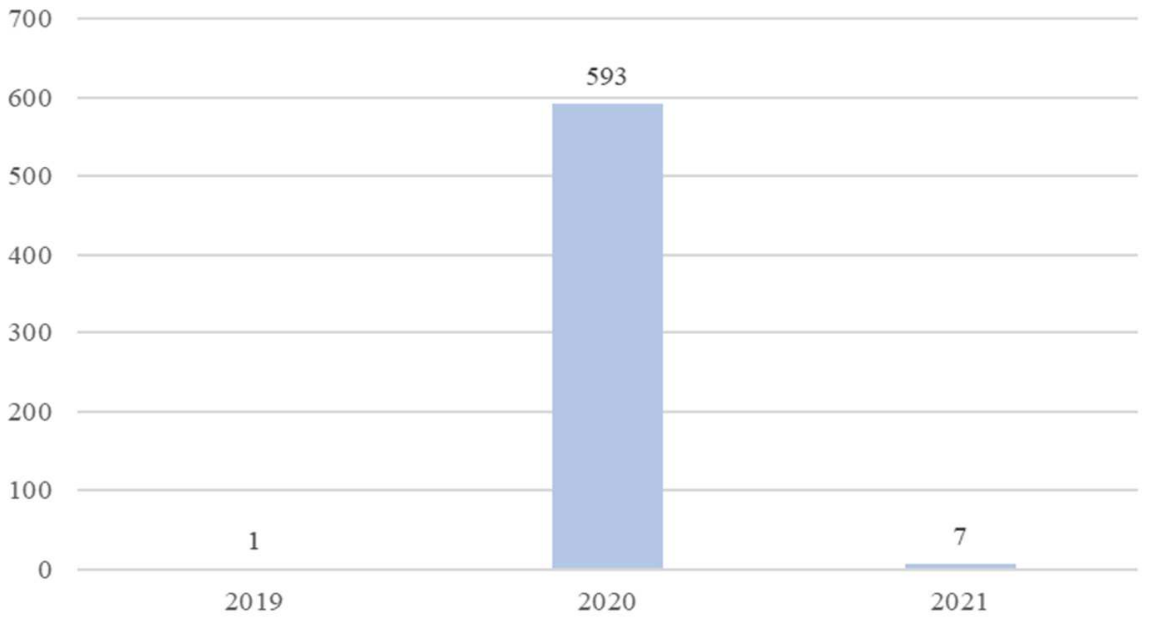


Figure 3. The different publication categories

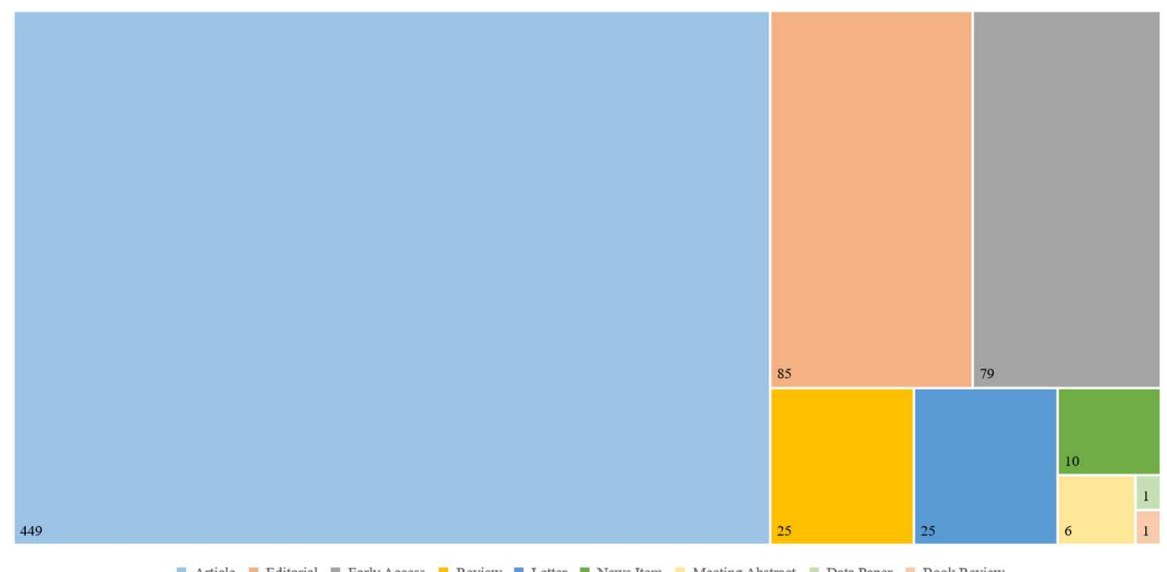

Figure 4. The TP, TC and H-index of the top-11 sources

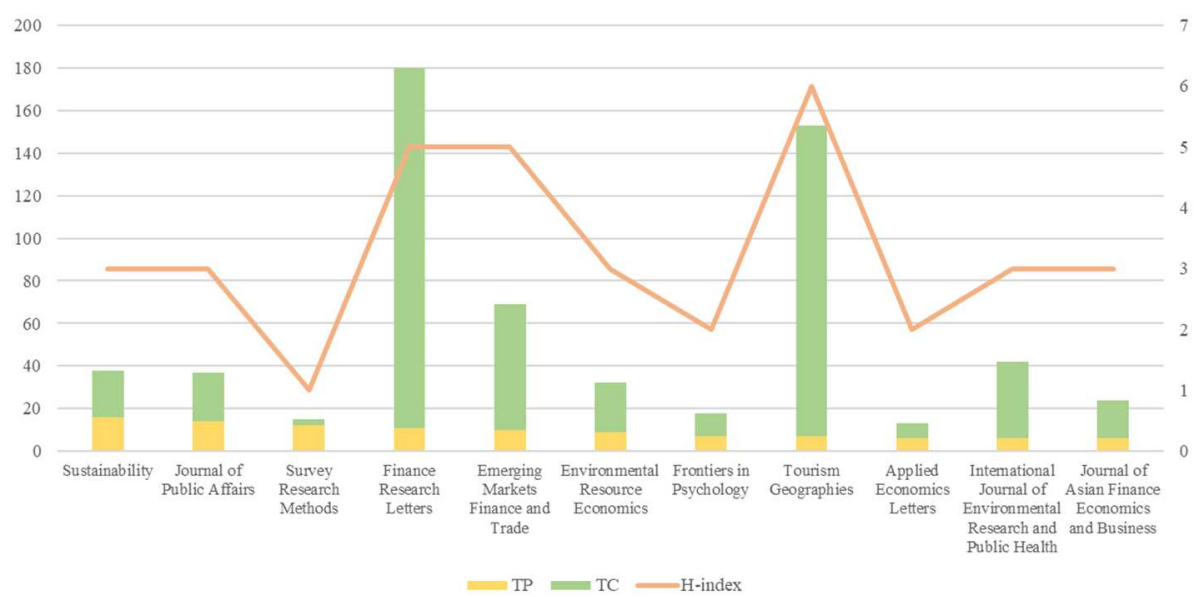


Figure 5. The distribution on different countries/regions

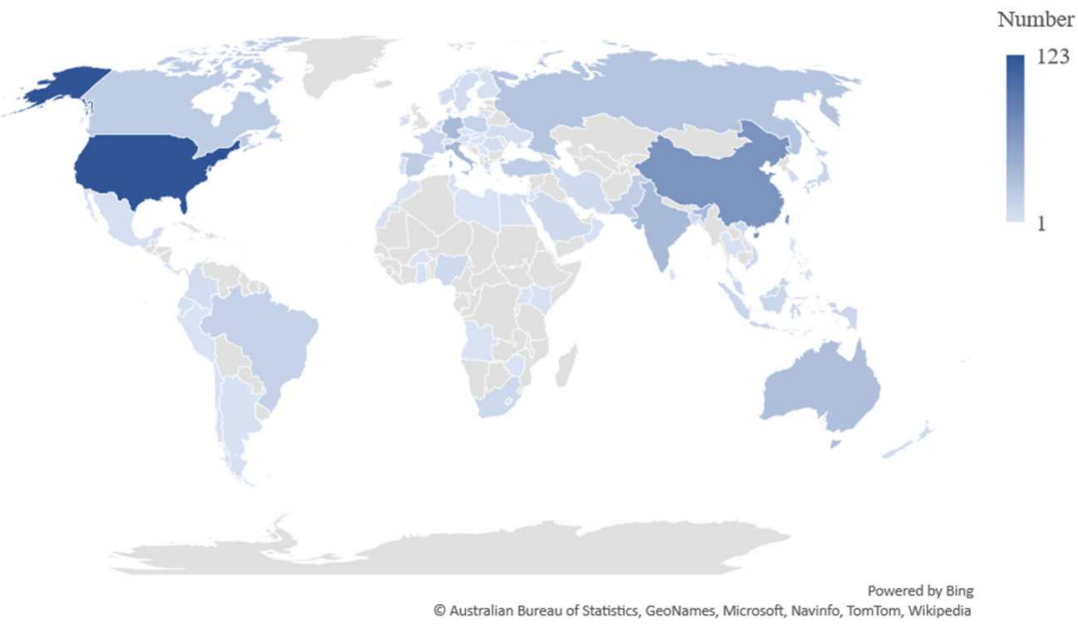

Figure 6. TP, TC, H-index of the top-10 prolific countries/regions

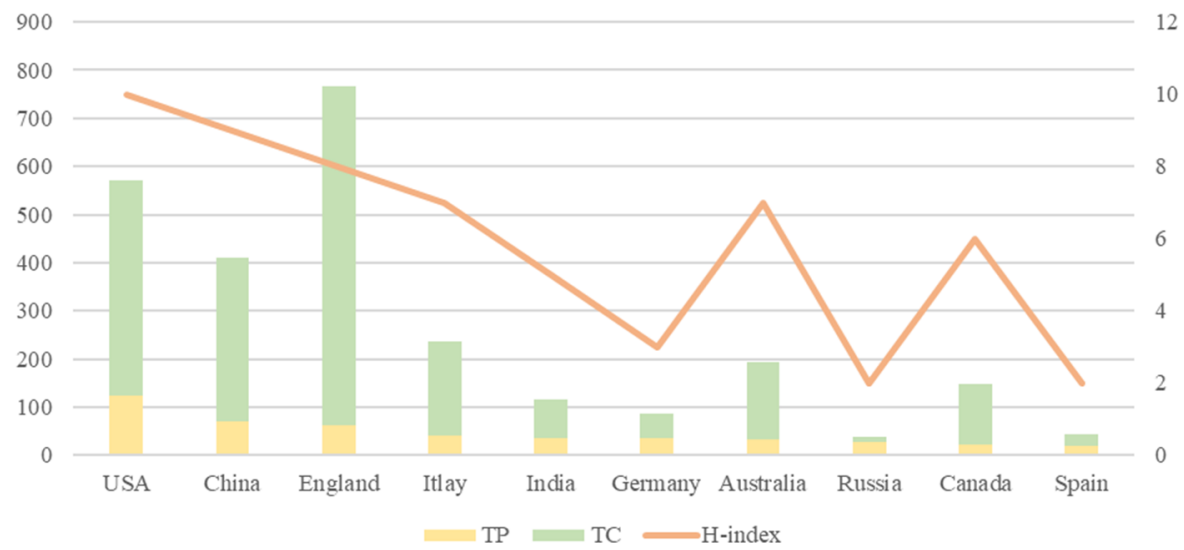




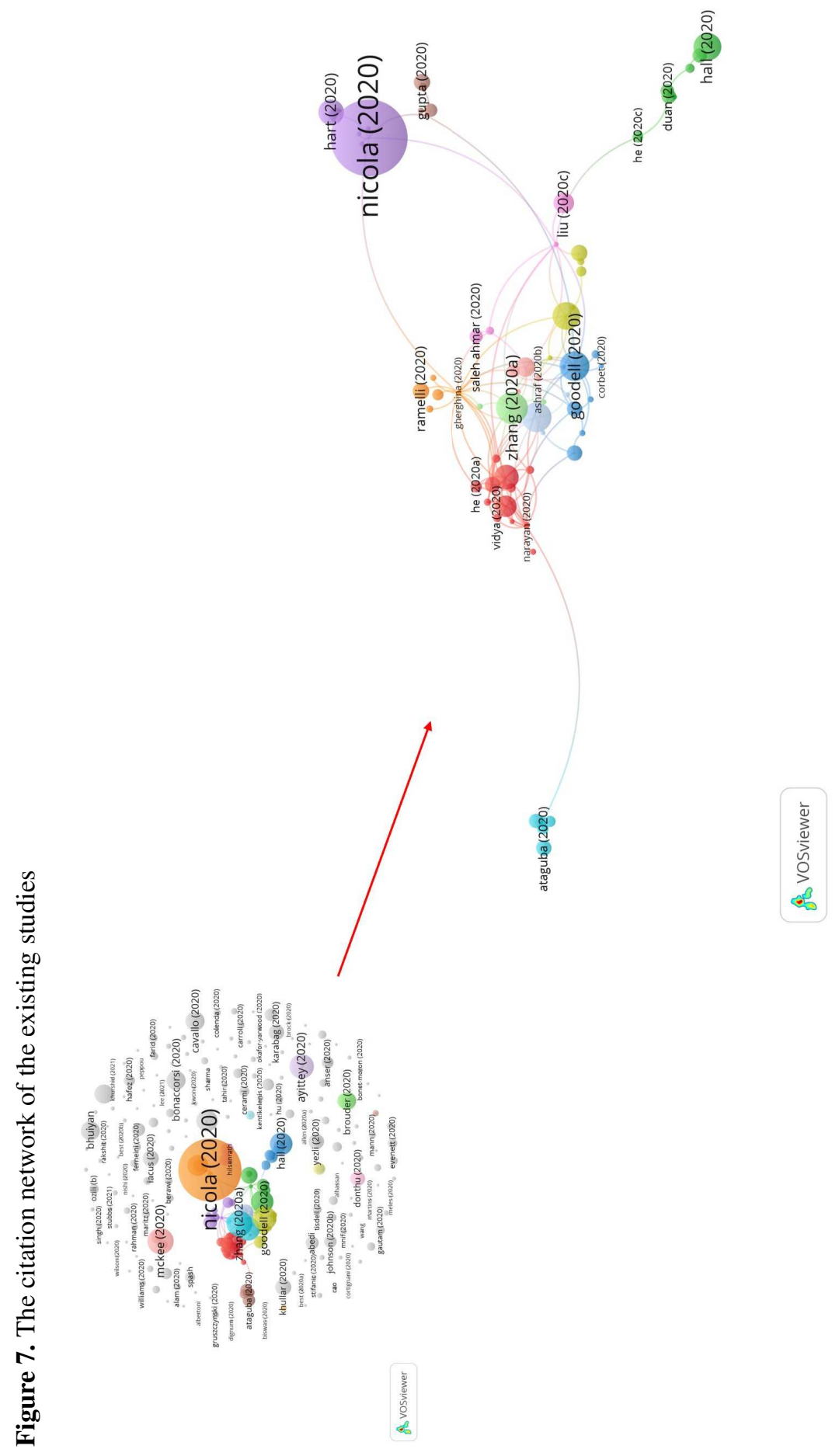




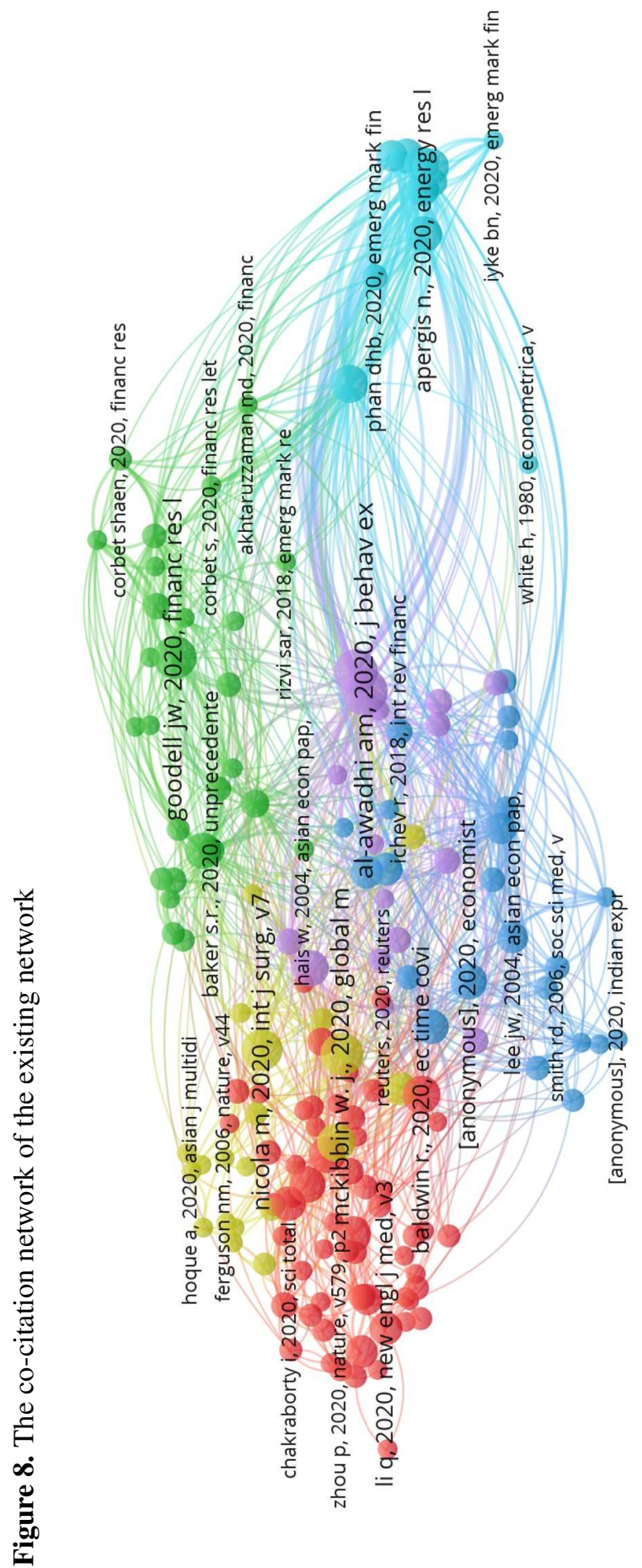

$\frac{1}{3}$ 


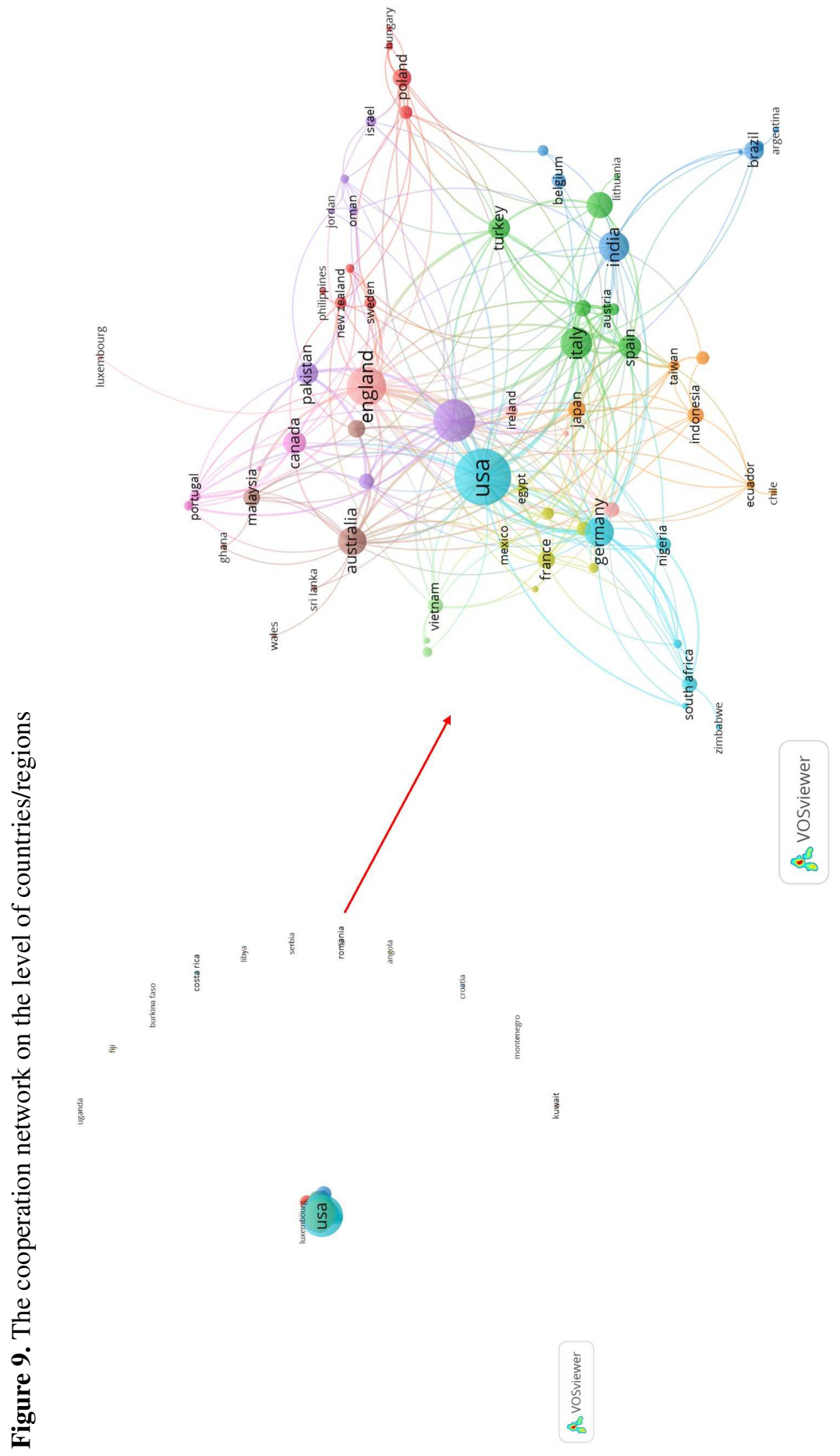




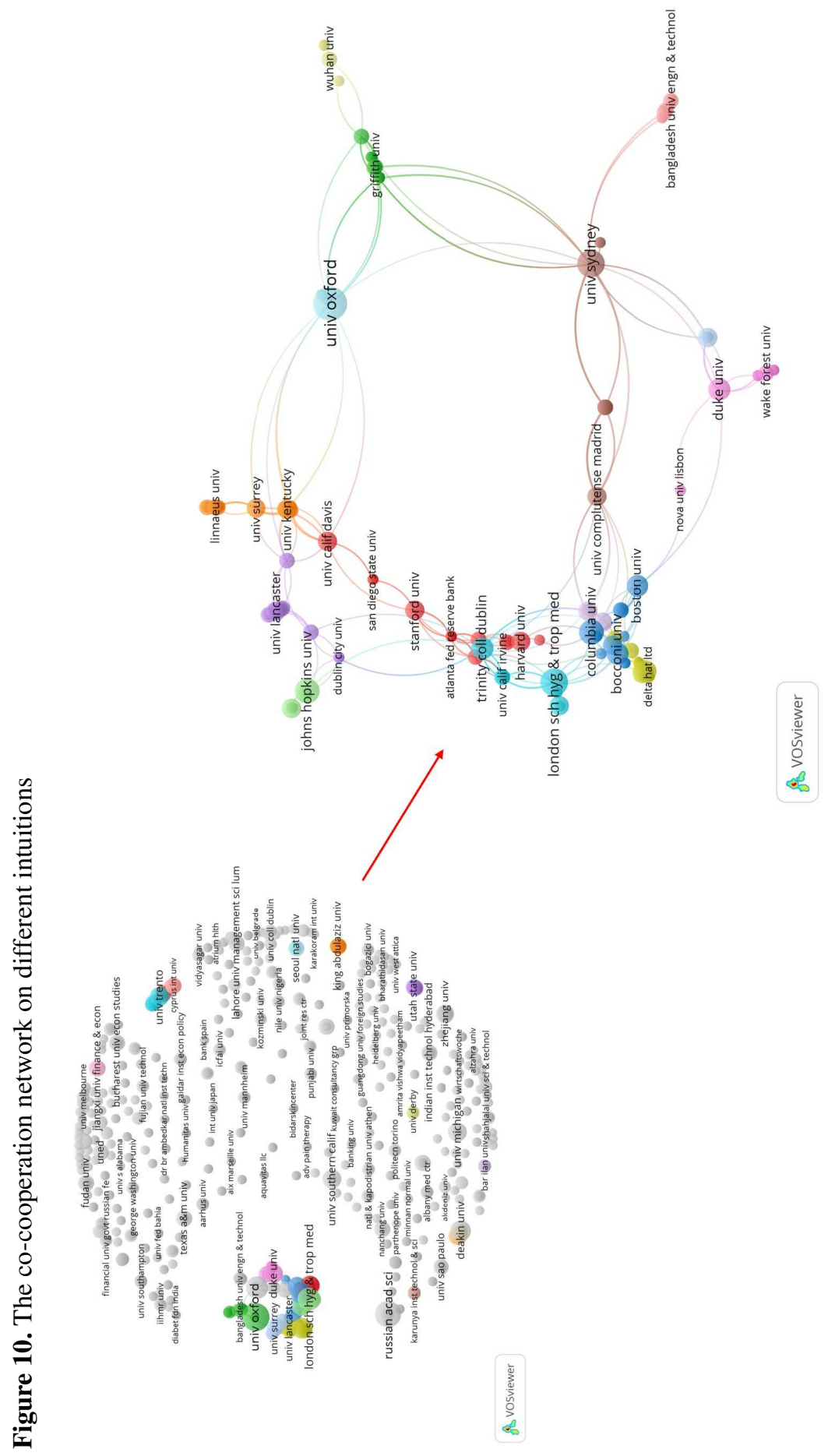




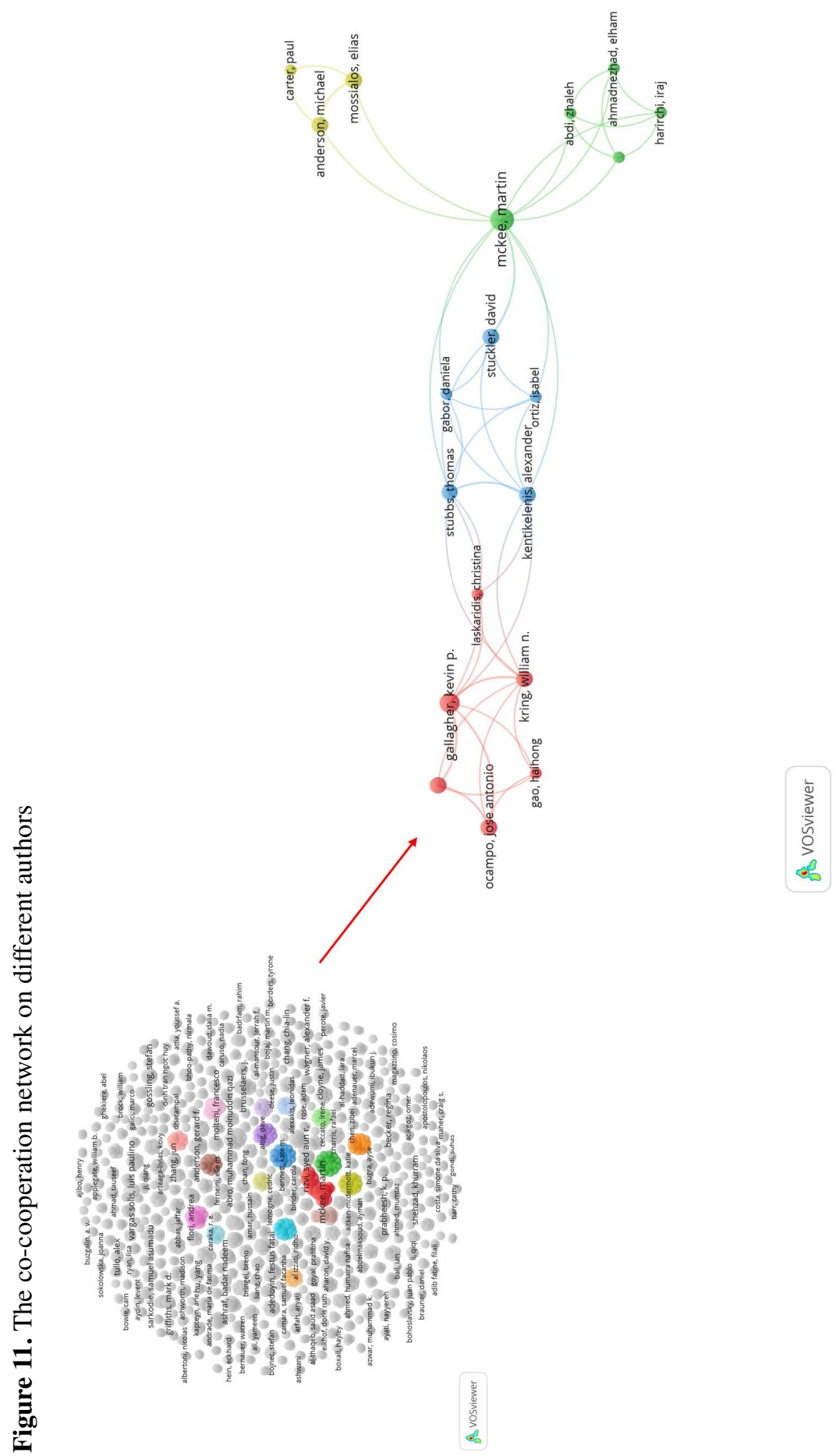




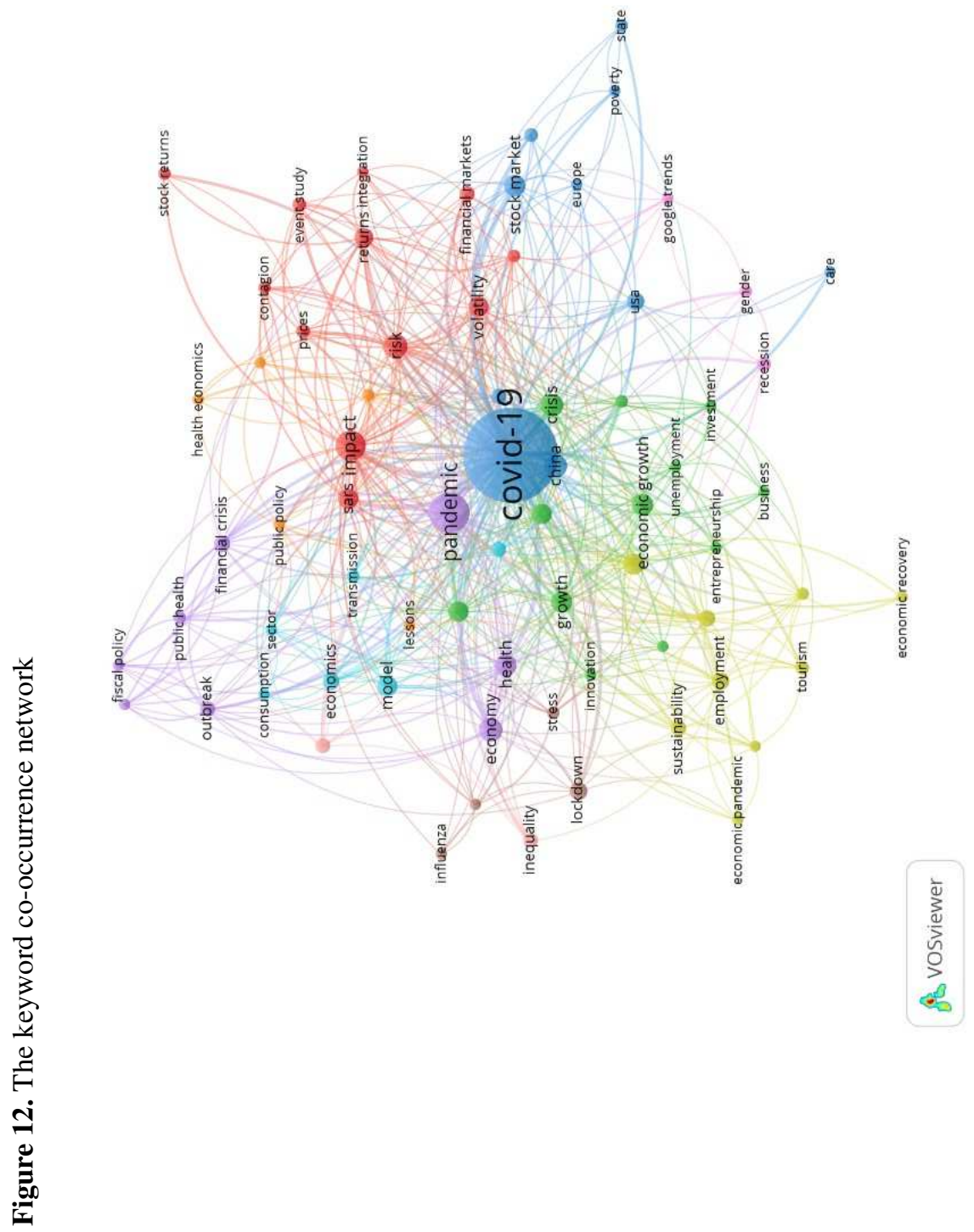



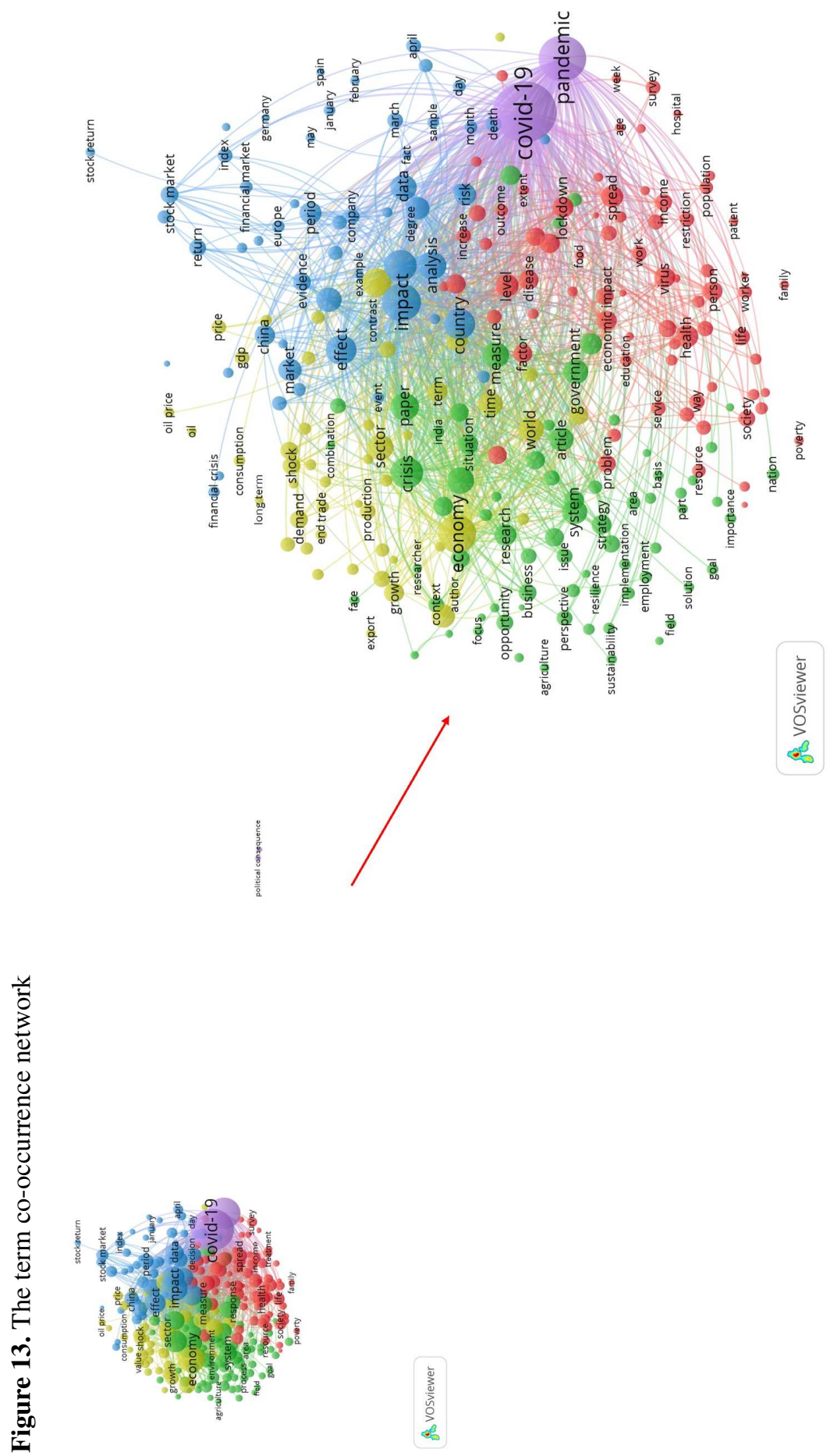
Figure 14. The framework of the theme analysis

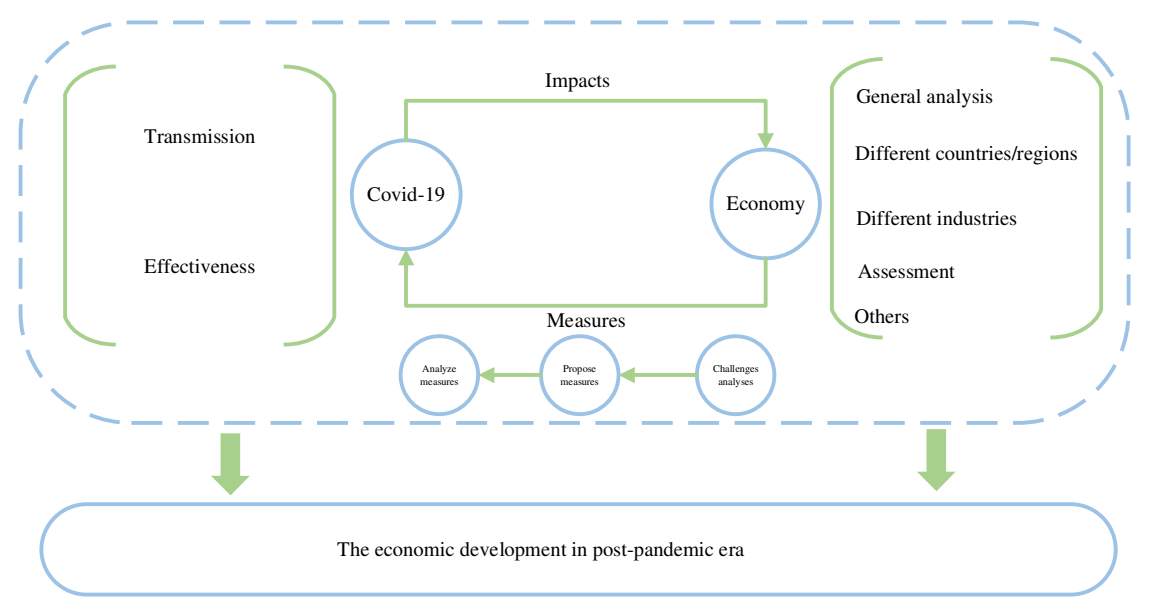

Figure 15. The classification of the studies about the pandemic's economic impacts on different industries

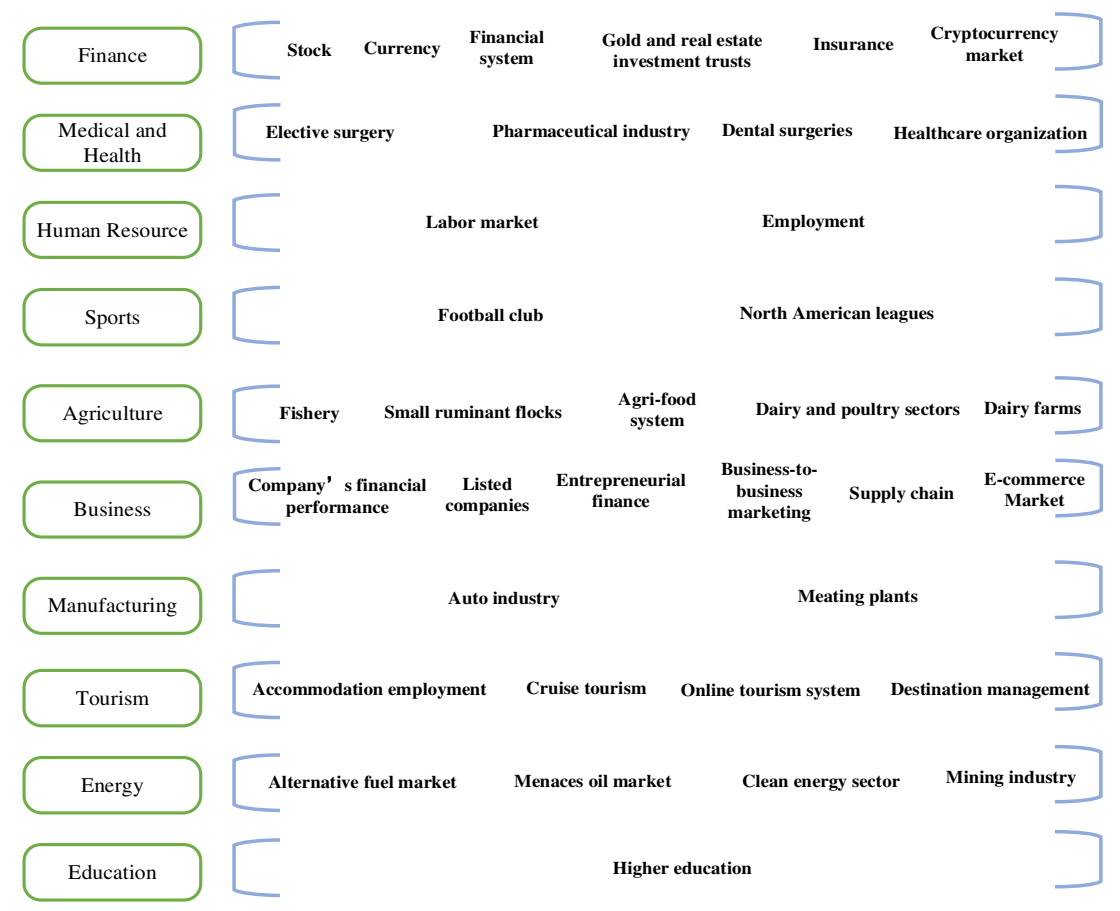

